\title{
A Model for Predicting the Heat Generation and Temperature in Friction Stir Welding from the Material Properties
}

Paul A. Colegrove1 (pac44@ cam.ac.uk), Hugh R. Shercliff ${ }^{1}$ (hrs@eng.cam.ac.uk), and Rudolf Zettler $^{2}$ (Rudolf.Zettler@gkss.de).

${ }^{1}$ Cambridge University, Dept. of Engineering, Trumpington Street, Cambridge CB2 1PZ, UK.

${ }^{2}$ GKSS-Forschungszentrum Geesthacht GmbH 


\begin{abstract}
This paper describes a simple numerical model for predicting the heat generation in friction stir welding (FSW) from the material hot deformation and thermal properties, the process parameters, and the tool and plate dimensions. The model idealises the deformation zone as a 2D axisymmetric problem, but allowance is made for the effect of translation by averaging the 3D temperature distribution round the tool in the real weld. The model successfully predicts the weld temperature field, and has been applied with minimal re-calibration to aerospace aluminium alloys 2024, 7449 and 6013, which span a wide range of strength. The conditions under the tool are presented as novel maps of flow stress against temperature and strain-rate, giving insight into the relationship between material properties and optimum welding conditions. This highlights the need in FSW for experimental high strain-rate tests close to the solidus temperature. The model is used to illustrate the optimisation of process conditions such as rotation speed in a given alloy, and to demonstrate the sensitivity to key parameters such as contact radius under the shoulder, and the choice of stick or slip conditions. The aim of the model is to provide a predictive capability for FSW temperature fields directly from the material properties and weld conditions, without recourse to complex CFD software. This will enable simpler integration with models for prediction of, for example, the weld microstructure and properties.
\end{abstract}

\title{
1. Introduction
}

Airbus are interested in applying Friction Stir Welding to joints in the wing, centre wingbox and fuselage ${ }^{1}$. Some of the materials being considered are 2024, 7449 and 6013 aluminium alloys. Most of the development work has been empirical, for example previous work on $2024^{2}$ has used experimental methods to determine the effect of weld pitch and tool type on the flow, temperature and deformation region size. Modelling of FSW can potentially accelerate the development process, and has been reviewed by Shercliff and Colegrove ${ }^{3}$. A central issue in all cases is the determination of the heat input. Models that predict the heat generation in Friction Stir Welding usually use some form of friction model ${ }^{4-35}$ which uses a constant coefficient of friction, or by assuming a constant interface shear stress. Several methods are used to calibrate heat flow models in order to determine the weld temperature. The primary method is to fit the model to experimental temperature data, by adjusting the heat input and the heat loss to the backing plate ${ }^{9-15,36}$. Alternative approaches use the measured power input to the weld as the heat input to the model ${ }^{18-23}$, or use characteristics of the weld microstructure to predict isotherms from which the heat input can be estimated ${ }^{8}$.

None of these approaches enable the heat generation and weld temperature to be predicted without an experimental measurement of some kind. A more accurate and predictive approach uses the 3 dimensional flow field to calculate the heat generation from the material viscous dissipation ${ }^{37-53}$. Even with these more sophisticated models there is conjecture over the best ways to describe the material behaviour, and the interface between the workpiece material and the tool, i.e. is there stick or slip. Therefore, the seemingly simple task of predicting the weld heat generation has proved beyond the ability of most models.

The emphasis of this paper is on the development of a model that predicts the weld heat generation and temperature from the flow and thermal properties of the material being welded, the tool and plate dimensions and the process parameters. This model calculates the heat generation with a simple 2 dimensional flow calculation. As well as predicting the heat generation, this model is also used to understand the differences between hard and soft 
materials, different rotation speeds and stick and slip conditions on the shoulder. The main motivation of this work is to develop an efficient and flexible method for prediction of the temperature histories for a range of alloys, to couple to models that predict the weld microstructure and strength using the models developed by Kamp and Robson ${ }^{54}$.

\section{Thermal Heat Generation Model}

\subsection{Model Description}

The modelling approach involves coupling a 3 dimensional thermal model for calculating the heat flow to a 2 dimensional axisymmetric flow model for calculating the heat generation. A flow diagram showing the coupling between these two models is shown in Figure 1. The 'Translating 3D Thermal Model' is solved in steady-state and predicts the temperature field around the tool from the heat flux applied at the tool-workpiece interface. This model captures the effect of tool translation. An averaged temperature field from this model is then imposed on the domain of the '2D Axisymmetric Flow Model'. The temperature affects the flow strength or viscosity of the material in the 2 dimensional model. The '2D Axisymmetric Flow Model' calculates the flow of material through a cross-section underneath the tool shoulder which is shown in Figure 2. This model is solved and the effective heat flux across the tool surface is found from the material flow strength. This heat flux is imposed on the 'Translating 3D Thermal Model' which is then solved using the updated heat flux. The process is repeated until the solution converges, i.e. there is no further change in the heat generation, temperature and flow fields. The starting point for the calculation is an isothermal temperature distribution of $500^{\circ} \mathrm{C}$. The details of these models and the coupling between them are summarised in the following sections.

This modelling approach has several advantages over conventional 3 dimensional thermal/flow models. Firstly, the 2 dimensional flow model is more computationally efficient than a 3 dimensional flow model. Secondly, the thermal model is now symmetric about the weld centreline, so its size can be halved.

\subsection{Translating 3D Thermal Model}

The steady-state thermal model was created in FLUENT $^{55}$ and calculates the heat flow during welding which involves solving the following differential equation:

$$
\nabla \cdot(\mathbf{v} \rho h)=\nabla \cdot(k \nabla T)+S_{h}
$$

where:

$\mathbf{v}$ is the velocity vector and equals $\left[v_{\text {weld }} 00\right]$.

$v_{\text {weld }}$ is the welding speed.

$\rho$ is the density.

$h$ is the sensible enthalpy, $\int_{T_{r e f}}^{T} c_{p} d T$.

$k$ is the thermal conductivity.

$T$ is the temperature.

$S_{h}$ is the volumetric heat source.

Note that the $x$ axis is in the welding direction, the $y$ axis is transverse to the welding direction and the $z$ axis is normal to the plate surface.

This model captures the effect of the tool translation, the thermal boundary conditions for the plate and the thermal properties of the material being welded and is used to predict the 
temperature near the tool surface. Although FLUENT has been used in this instance, any package that calculates heat flow could have been used.

This temperature field is then used to calculate the average temperature at a given depth, $z$ and radial position, $r$ in the 2 dimensional axisymmetric domain of the flow model. This is done with the following equation:

$$
T_{2 D}(r, z)=\frac{\int_{0}^{\pi} T_{3 D}(r, z, \theta) d \theta}{\pi}
$$

where:

$T_{2 D}$ and $T_{3 D}$ are the 2 and 3 dimensional temperature fields respectively.

$r, z$ and $\theta$ are cylindrical coordinates with origin at the tool rotation axis.

Note that $\theta=0$ along the positive $x$ axis and $\theta=\pi$ along the negative $x$ axis, and that the 3 dimensional thermal field is symmetric about the weld centreline.

The temperature averaging achieved with this equation is illustrated in Figure 3 . This shows the temperature under the shoulder in the 3 dimensional translating thermal model and the corresponding average temperature in the 2 dimensional axisymmetric flow model. This temperature averaging has a similar effect to the mixing induced by the rotating tool, i.e. the mixing results in a more uniform temperature around the tool, as demonstrated in Colegrove and Shercliff ${ }^{17}$.

\subsection{D Axisymmetric Flow Model}

The 2 dimensional axisymmetric flow model predicts the rotational flow around the tool, ignoring the translating flow, which involves solving the following differential equation:

$$
\frac{\partial}{\partial z}\left(r \mu \frac{\partial w}{\partial z}\right)+\frac{1}{r} \frac{\partial}{\partial r}\left(r^{3} \mu \frac{\partial}{\partial r}\left(\frac{w}{r}\right)\right)=0
$$

where:

$r$ and $z$ are the cylindrical coordinates.

$w$ is the swirl or rotational velocity.

$\mu$ is the viscosity and equals $\sigma / 3 \overline{\dot{\varepsilon}}$.

$\sigma$ is the material flow strength and is a function of the temperature and strain-rate. The temperature is the averaged temperature from the '3D Translating Thermal Model'. The function used to determine flow strength is described in the next section.

$\overline{\dot{\varepsilon}}$ is the effective strain-rate.

The velocity equals the rotational velocity $(r \omega)$ at the tool interface and zero at the other boundaries, as shown in Figure 2. Slip is considered in some of the models, the details of which are described in section 5.2. The analysis ignores the translational flow past the tool and the effect of threads and tool features. The justification for making these assumptions is provided in section 3 . Once the flow has been calculated the heat flux across the pin and shoulder surfaces is found with:

$$
\dot{Q}=\mu \overline{\dot{\varepsilon}} r \omega
$$

which is a product of the shear stress at the surface and the wall velocity.

\subsection{The Material Flow Strength}

The material 'flow strength' refers to the steady-state flow strength of the material and 
ignores work hardening. When modelling the flow with this approach it is not possible to include the material's elastic properties. This is one reason why a coefficient of friction cannot be easily used, since the normal stress below the shoulder is not known. The equation used to describe the flow strength of aluminium alloys was proposed by Sellars and Tegart ${ }^{56}$ and was modified by Sheppard and Wright ${ }^{57}$.

$$
Z=\overline{\dot{\varepsilon}} \exp \left(\frac{Q}{R T}\right)=A(\sinh \alpha \sigma)^{n}
$$

where:

$\overline{\dot{\varepsilon}}$ is the equivalent strain-rate(/s) and is given by:

$$
\overline{\dot{\varepsilon}}=\sqrt{2 / 3 \dot{\boldsymbol{\varepsilon}} \cdot \dot{\boldsymbol{\varepsilon}}}
$$

$Q$ is the activation energy. $(\mathrm{J} / \mathrm{mol})$

$R$ is the universal gas constant. $(\mathrm{J} / \mathrm{kg} \mathrm{K})$

$T$ is the temperature. $(\mathrm{K})$

$A, \alpha, n$ are material constants.

$\sigma$ is the equivalent steady-state flow stress (MPa)

While this relationship holds at conventional hot working temperatures, near the solidus significant softening will occur. This softening is included in the models by linearly reducing the flow strength from the Zener-Hollomon value at an arbitrarily defined softening temperature $T_{m}$ to zero at the solidus temperature $T_{s}$. This region is called the 'Empirical Softening Regime'. A similar viscosity softening approach was proposed by Seidel and Reynolds $^{53}$. The resultant curves for the materials used in this paper are shown in Figure 4, and the Zener-Hollomon constants, solidus temperatures and sources of data for each of the materials is summarised in Table 1. The size of the Empirical Softening Regime $\left(T_{s}-T_{m}\right)$ is arbitrarily set to $50^{\circ} \mathrm{C}$ for each material. The effect of adjusting this temperature range is explained in section 3 .

\subsection{Application of the Model}

To validate this model, it is first applied to a sample weld in $6.35 \mathrm{~mm}$ thick 7449 aluminium alloy and the parameters that have the greatest impact on the heat generation are investigated. The model is also compared against a fully coupled 3 dimensional thermal/flow model to determine whether the simplification described above is valid. The model was then applied to a series of 2024-T351 and 6013-T6 Friction Stir Welds to determine how well the model can predict the heat generation and weld temperature field, purely from the process parameters and the properties of the material being welded.

\section{Justification and Parametric Study}

Section 2 described how the 2 dimensional axisymmetric heat generation model works but gave no justification for using this approach. This section addresses this question by testing the approach on a weld in 7449 aluminium alloy and also describes a parametric study for understanding the sensitivity of the heat input to key material and process variables. The material softening behaviour (i.e. values of $T_{m}$ and $T_{s}$ ) is examined because this aspect of the curve has not been experimentally validated. Note that all the models in this section use a stick boundary condition at the pin and shoulder. 


\subsection{Experimental}

The analysis was done on a single $6.35 \mathrm{~mm}$ thick $7449-\mathrm{T} 7351$ Friction Stir Weld made at TWI, Cambridge using the Trivex Friction Stir welding tool ${ }^{52}$ shown in Figure 5. The Trivex tool had a minimum pin radius of $4 \mathrm{~mm}$ at the tip and a maximum pin radius of $5.1 \mathrm{~mm}$ where the pin meets the shoulder and a shoulder radius of $11.5 \mathrm{~mm}$. A rotation speed of $350 \mathrm{rpm}$ and a welding speed of $350 \mathrm{~mm} / \mathrm{min}$ were used for this weld.

\subsection{Parametric Study}

\subsubsection{Description}

Using the model concept described in section 2.1 a thermal model was developed to simulate the weld described above. This was virtually identical to the model described in Colegrove and Shercliff ${ }^{17,48}$.

The parametric study explores the sensitivity of the heat generation to the solidus temperature while keeping the softening regime, $\left(\mathrm{T}_{\mathrm{s}}-\mathrm{T}_{\mathrm{m}}\right)$ equal to $50^{\circ} \mathrm{C}$. A second analysis explores the effect of changing the softening regime size while keeping the solidus temperature constant at $500^{\circ} \mathrm{C}$.

Another area of uncertainty is the contact between the tool shoulder and the material being welded. In welds where the tool is raked away from the direction of travel (as in this experimental weld), it is often found that there is incomplete contact between the leading edge of the shoulder and the welded material. This is evident around the exit hole after the tool is withdrawn. Another possibility is that a slip condition may exist between the welded material and the tool shoulder. Indeed Valberg and Malvik ${ }^{59}$ have shown that in the related process of extrusion a stick condition exists in some areas of the die while a slip condition exists in others. Irrespective of whether the shoulder contact is complete or incomplete and whether stick, slip or both occur, the actual heat generation will be less than that for full shoulder contact (and stick). Both these effects are accounted for by defining the 'contact radius' for the shoulder. The parametric study investigates how the heat generation is affected by varying the contact radius from $8.5 \mathrm{~mm}$ to the actual radius of $11.5 \mathrm{~mm}$.

Schmidt and Hattel ${ }^{47}$ have used an alternative method that uses full shoulder contact and a coefficient of friction to describe the slip behaviour. This method results in stick on some parts of the tool and slip on others. Although this method may be more physically realistic it was not possible to get a single coefficient of friction that is applicable in all welding conditions in the same way as it is possible to get a single contact radius. Furthermore the use of friction coefficients requires a knowledge of the normal stress under the shoulder.

\subsubsection{Results and Discussion}

Figure 6(a)-(b) show plots of the weld power versus the shoulder contact radius and the solidus temperature (Figure 6(a)) and the size of the softening regime (Figure 6(b)). Note that an infinite solidus temperature is included in Figure 6(a) to show what happens when there is no material softening. These plots show that the shape of the softening regime has a smaller effect on the heat generation (4\%) than the shoulder contact radius $(20 \%)$ over the parameter range investigated. The increase in heat generation with the shoulder contact radius is a consequence of the greater area of contact (which increases with the square of the radius) and the greater surface velocity (which increases with the radius). Note however that the softening of the material with temperature moderates this increase. 
The relative insensitivity of the heat generation to the softening behaviour is a great advantage. This means that the constitutive models described in section 2.4 can be used despite the limited understanding of the behaviour at temperatures approaching the solidus. However, softening of some description as the solidus is approached is essential to avoid excessive heat inputs and weld temperatures. Finally, by comparing the temperature profiles from experiment with those from the model it was possible to estimate a weld heat input of $3 \mathrm{~kW}$. From Figure 6(a) this value is consistent with the model only if the shoulder contact is incomplete.

\subsection{Justification for the 2 Dimensional Axisymmetric Flow Model}

The 2 dimensional axisymmetric flow model ignores many of the real process characteristics such as the flow round the tool, the profiled pin geometry of the Trivex tool (see Figure 5) and the flow under the pin. To determine whether these characteristics affect the heat generation significantly a coupled 3 dimensional thermal/flow model was created in FLUENT which included all these effects. The model is divided into two Eulerian regions: a rotating region around the tool where the mesh moves at the rotation speed of the tool, and a surrounding stationary region, which models the flow in the far field. This model calculated both the flow and thermal fields, with the heat generation coming from viscous dissipation. Three different contact radii were analysed with the standard material behaviour shown in Figure 4(a). The result of the comparison is close agreement between the fully coupled 3 dimensional model and the 2 dimensional approximation, as shown in Figure 6(c). This validates the use of the 2 dimensional axisymmetric flow model. There are several reasons why the simplification works. Firstly, as discussed in section 2.2, the temperature averaging has a similar effect to the mixing induced by the rotating tool. Therefore the averaged temperature in the 2 dimensional axisymmetric flow model is similar to the temperature in the fully coupled model which includes material mixing. Secondly, the main determinant of the heat generation is the temperature at the surface of the tool, which in turn determines the flow stress. Provided this can be modelled reasonably accurately, the prediction of the heat generation is good. Finally, the kinematics of the process are such that rotational flow in the plane of the plate dominates, compared to the translational motion of the tool, and the vertical motion of material induced by tool features.

This comparison has not included threads on the pin, which are used in most commercial FSW tools. A previous paper ${ }^{49}$ compared a threaded pin against a cylindrical one and found no difference in the heat generation when using a stick boundary condition. Hence the technique is valid for all pin profiles where the material is stuck to the pin.

\section{Application to Thin Plate 2024 and 6013}

Having established the simplified method of predicting the heat generation and the importance of the shoulder contact radius, this section applies the technique to a series of Friction Stir Welds in 3.2mm thick 2024-T351 and 4mm thick 6013-T6. The aim is to test the ability of the model to predict the heat generation, and temperature field, directly from the flow properties and process conditions, with minimal further calibration.

\subsection{Experimental}

The experimental welds were made at GKSS, Geesthacht Germany using the Tricept TR 805 robot. The plates used for the welds were 3.2mm thick 2024-T351 and 4mm thick 6013-T6 aluminium alloy and were $395 \mathrm{~mm}$ long and $110 \mathrm{~mm}$ wide. Prior to welding, each plate was 
manually ground with $1200 \mathrm{SiC}$ paper and cleaned with acetone. The tools used to make the welds had a tapered pin with a thread and three flats with diameters of $15 \mathrm{~mm}$ for the 2024T351 welds and $13 \mathrm{~mm}$ for the 6013 -T6 welds. A scroll shoulder was used which enabled the welds to be made with the tool normal to the plate surface.

The main aspects of the welding layout are shown in Figure 7. Six thermocouples were inserted in each 2024-T351 plate prior to welding and were spaced at distances of 10, 15 and $20 \mathrm{~mm}$ ( $y$ direction) at depths of 1 and $2.2 \mathrm{~mm}$ from the top surface. A further 7 thermocouples were placed in the backing bar at a depth of $0.75 \mathrm{~mm}$ from the workpiece which enabled the heat transfer to the backing plate to be calibrated. Only 3 thermocouples were used in each plate of 6013-T6 and were placed at the same distances from the centreline $(10,15$ and $20 \mathrm{~mm})$ at a depth of $2 \mathrm{~mm}$.

Table 2 shows the parameter combinations of welding and rotation speeds used for the 2024T351 welds. A total of 14 welds were made with two welds being produced at $800 \mathrm{rpm}$ and $200 \mathrm{~mm} / \mathrm{min}$. The vertical load (force as measured in the $z$ direction) is indicated. Only four welds were made using 6013-T6. Three had a welding speed of $900 \mathrm{~mm} / \mathrm{min}$, with rotation speeds of 1200, 1400 and $1700 \mathrm{rpm}$, while the last had a welding speed of $450 \mathrm{~mm} / \mathrm{min}$ and a rotation speed of $900 \mathrm{rpm}$.

Weld macrosections were made of each of the welds. The rotation speed had the greatest impact on the appearance of the weld macrosections with the welding speed having a minor effect.

\subsubsection{Traversing Force}

On the 2024-T351 welds forces were measured with a Kistler 9366BB force table. The traversing force results ( $x$ direction) are shown in Figure 8 with the data points being average values from the steady-state section of the weld. The traversing force always increased with welding speed, however there is an 'optimum' rotation speed that minimises the traversing force. For example, at a welding speed of $200-400 \mathrm{~mm} / \mathrm{min}$ the traversing force is minimised with a rotation speed of 800-1200 rpm. Using a rotation speed either higher $(1600 \mathrm{rpm})$ or lower $(400 \mathrm{rpm})$ resulted in a greater value. This minimum has been observed by other authors $^{60,61}$, and can be explained with process modelling ${ }^{61,62}$.

\subsubsection{Weld Temperature}

An example of the experimental weld thermal cycles (compared with the modelling result) is shown in Figure 9. The temperatures measured on the retreating side were on average $18^{\circ} \mathrm{C}$ higher than those measured on the advancing side for the thermocouples $10 \mathrm{~mm}$ from the tool. There are two suggested causes of this effect. The first is that the difference is a consequence of material mixing; however, models of the process indicate that the temperature distribution around the tool is uniform and that if anything a hot spot occurs on the advancing side. An alternative explanation is that there is better contact between the welded material and the tool shoulder on the retreating side due to the flow and/or side force (which may cause a small deflection of the tool).

The temperature results from the two welds at $800 \mathrm{rpm}$ and $200 \mathrm{~mm} / \mathrm{min}$ showed that the peak temperature (and heat input) were dependent on the normal load. The peak temperature with the higher normal load was approximately $15^{\circ} \mathrm{C}$ greater than the lower load weld across all the thermocouple positions. Increasing temperature or heat input with normal load has also been observed by Tang et al. ${ }^{63}$ and Yan et al. ${ }^{60}$, although the effect in the latter paper was 
weak. The increase is believed to be due to either a slightly larger area of contact between the tool shoulder and the welded material, or a better frictional coupling between the two because of the higher interface pressure.

\subsection{Description of the Model}

\subsubsection{Thermal Model}

The extensive thermocouple measurements, particularly those in the backing bar, enabled a good understanding of the heat flow during the process. The combined backing bar/vacuum table (see Figure 7) made the model more complicated than using a single backing bar of one material. Figure 7 summarises the steady-state thermal model and the boundary conditions, which are shown in grey. Only the workpiece, backing bar and tool are included with the heat loss under the backing bar and workpiece being modelled with convective heat transfer.

There are four different pathways for heat loss, which are all shown in Figure 7. The first pathway involves the heat being transferred into the workpiece and then into the backing bar. Two different contact resistances were used between the workpiece and the backing bar. Underneath and behind the shoulder (shown in grey), a region with a low contact resistance, $R_{1}$ was used because the deformation in the process flattens the surface asperities which results in good thermal contact. Ahead and to the side of this region there is a much higher contact resistance, $R_{2}$ because these areas are not influenced by the welding process. Finally the heat that is conducted into the backing bar is then lost to the body of the vacuum table and is modelled with convective heat transfer with coefficient $h_{b}$.

The second pathway again involves the heat being conducted into the workpiece, however it is conducted further away from the tool and is lost to the vacuum table in the far field. Like the bottom of the backing bar, this heat loss is modelled with convective heat transfer and has a coefficient $h_{v}$. The third pathway is similar except that heat is lost from the top surface of the workpiece via convection. The convective heat transfer coefficient used is $10 \mathrm{~W} / \mathrm{m}^{2} \mathrm{~K}$. The fourth pathway is the heat that is lost through the tool via conduction. This is calculated by finding the 1 dimensional conductive heat loss along a tool of length $100 \mathrm{~mm}$ with the far end at ambient temperature. Of the four pathways the first is by far the most significant followed by the second. The third and fourth pathways have little effect on the result, but are included for completeness. The values of the four key boundary conditions $R_{l}, R_{2}, h_{b}$ and $h_{v}$ are summarised in Table 3 and were found by trial and error: Note that with so many adjustable parameters, fitting the thermocouple data to the model was difficult. The values determined are not necessarily the 'correct' ones, but gave a reasonable fit to the experimental data over a wide range welding conditions.

Constant values of thermal conductivity of $120 \mathrm{~W} / \mathrm{mK}^{64}$ for $2024-\mathrm{T} 351$ and $164 \mathrm{~W} / \mathrm{mK}^{65}$ for 6013-T6 were used in the models. Obtaining an accurate estimate of the temperature dependent thermal conductivity is difficult because the value is sensitive to the condition of the material, i.e. the amount of solute. Data book values ${ }^{66}$ often give the thermal conductivity at equilibrium and are therefore not representative of the thermal conductivity during welding where the thermal cycle is very short. However, with such a small volume of material being affected by the process (as represented by the HAZ), the use of room temperature values is reasonable and gives a better correlation with thermocouple measurements than temperaturedependent values. 


\subsubsection{Material Constitutive Behaviour}

The constitutive material models for both 2024 and 2014 aluminium alloys were used to describe 2024, with the details being shown in Table 1 and Figure 4(b). There are several reasons for including 2014 in the analysis. Firstly, 2014 is a similar alloy to 2024 but has a smaller amount of Magnesium (0.2 to $0.8 \%$ compared with 1.2 to $1.8 \%$ ) which results in it being softer. However, as seen in Figure 4(a), there is almost a factor of 2 difference in the flow strength of the two materials based on the constants from Sheppard and Jackson ${ }^{58}$. Data for 2024 from an independent source (Alcan) showed the flow strength to be closer to that for 2014. Although there was insufficient data for a constitutive model, the values suggest that the very high values for 2024 from Sheppard and Jackson ${ }^{58}$ may be incorrect. Another benefit of including the two materials is that it enables the difference between hard and soft materials to be determined.

Finally the flow behaviour of 6013 was represented by a similar alloy, 6056. The two alloys are almost identical apart from the composition ranges which are smaller for 6013. The Zener-Hollomon parameters for 6056 were found by regression analysis on experimental data.

\subsubsection{Shoulder Contact Radius}

As mentioned in section 3 , the shoulder contact radius has a significant impact on the heat generated by the model and needs to be calibrated. The values that gave the best fit to the experimental data were $4.8 \mathrm{~mm}$ for the 2024 constitutive model and $5.1 \mathrm{~mm}$ for the 2014 constitutive model. These values were then fixed and the thermal profiles found for the different rotation and welding speeds.

Finally the shoulder contact radius for the 6013 welds was found by scaling the $5.1 \mathrm{~mm}$ value used for 2014 with the shoulder diameter which gave a value of $4.45 \mathrm{~mm}$. Note an important difference between the 2024 and 6013 models. The former model was used to calibrate the shoulder contact radius while the latter was used to test whether this same value could be applied directly to a new material.

\subsubsection{Heat Generation and Temperature}

The level of agreement with the experimental thermal cycles varied somewhat for different welding parameters. A plot comparing one of the better predictions with the thermocouple data is shown in Figure 9. One way of comparing the experimental and model results across all welds is to compare the peak temperature values. Figure 10 shows the difference between the models described above and the experimental results at a distance of $10 \mathrm{~mm}$ from the weld. A positive value indicates that the model over predicts the temperature while a negative value indicates that the model under predicts the temperature. The magnitude of the experimental values varied between $160^{\circ} \mathrm{C}$ and $310^{\circ} \mathrm{C}$ at this position. The values further from the tool (i.e. at 15 and 20mm) reflected those shown in Figure 10 but are smaller in magnitude due to the lower temperatures being measured. Both the 2024 and 2014 properties gave similar temperature predictions as indicated in the temperature differences in Figure 10(a). The greatest difference was at a rotation speed of 400rpm where the temperature with the 2024 material was greater due to a $5 \%$ higher heat generation with the harder material.

There are several reasons for the difference between the experimental and model results. Firstly, there is experimental variability, in particular in the axial load which affects the amount the tool plunges into the material and the amount of contact between the material and the tool shoulder. As shown in section 4.1.2, greater axial load increases the weld temperature. Therefore one reason for the model's poor prediction of the 1600rpm and 
$200 \mathrm{~mm} / \mathrm{min}$ weld temperature was the high axial load used for this experiment. The value of $9 \mathrm{kN}$ was greater than the 6 or $8 \mathrm{kN}$ used for the other welds that also used this welding speed. Other reasons for the discrepancy are the transient welding conditions that exist in practice, uncertainties in thermal conductivity, and thermal boundary conditions and the approximations in the heat generation model. Nevertheless the predictions are reasonable given the wide range of welding parameters and the variability in the experimental data. The discrepancies are close to the limit of accuracy in the measured temperatures

Finally, the temperature difference for the 6013 models in Figure 10(b) shows a very good prediction for all four welds. As mentioned earlier, the model was being used in a predictive sense, since the shoulder contact radius had already been established. This result is pleasing and suggests that the model is able to predict the weld temperature in a new alloy provided similar tools and weld setup are used.

\subsubsection{Comparison of the Heat Generation Between 2024 and 6013}

The heat generation in 2024-T3 and 6013-T6 is shown as a function of welding and rotation speed in Figure 11(a). In order to demonstrate the effect of changing the material alone, both materials were analysed with the parameters for the 2024-T3 welds. i.e. $3.2 \mathrm{~mm}$ thick material, a shoulder diameter of $15 \mathrm{~mm}$ and a contact radius of $5.1 \mathrm{~mm}$. Figure 11(a) shows how heat generation rises to a plateau with increasing rotation speed. This characteristic is also observed experimentally ${ }^{60}$.

The heat input is greater for 6013 than 2024, for all welding conditions except a rotation speed of $400 \mathrm{rpm}$. There are two reasons for this observation. Firstly, the thermal conductivity of 6013-T6 $(164 \mathrm{~W} / \mathrm{mK})$ is considerably higher than that of 2024-T3 (120 $\mathrm{W} / \mathrm{mK}$ ). This increases the heat loss from the weld and results in more heat being required to produce the same weld temperature. The second reason is the solidus temperature of 6013 $\left(579^{\circ} \mathrm{C}\right)$ is considerably higher than the solidus for $2024\left(502^{\circ} \mathrm{C}\right)$. Therefore the temperature at which softening occurs is much greater which allows more heat generation, particularly at the high rotation speeds. At low rotation speeds where the temperature of both materials is well below their respective solidus temperatures, the heat generation is lower with 6013. This is because the flow strength at temperatures prior to softening is lower with 6013 than 2024 . Hence more heat can be generated with the stronger 2024 alloy.

Finally, it is suggested that the 'ideal' rotation speed is at or just before the plateau in the heat generation. This corresponds to a rotation speed of 800-1000 for 2024 and 1200-1600 rpm for 6013. Interestingly, this rotation speed also corresponds to the minimum in traversing force (see section 4.1.1) and confirms the findings in a previous paper ${ }^{62}$. This effect is illustrated in Figure 11(b) which shows the heat generation, traversing force and peak temperature at the shoulder and root of the weld as a function of the rotation speed for a welding speed of $400 \mathrm{~mm} / \mathrm{min}$.

\section{Flow Behaviour of $3.2 \mathrm{~mm}$ Thick 2024}

The focus of the previous section was on the development of a model to predict the weld heat generation and temperature. In addition to predicting the heat generation, the 2 dimensional axisymmetric flow model also predicts the rotational flow around the tool, ignoring the tool translation. Although this model is simplified, useful information can be obtained from plots of the rotational flow and an analysis of the material deformation condition. The analysis is done for two welding conditions only; the $1600 \mathrm{rpm}$ and $200 \mathrm{~mm} / \mathrm{min}$ weld and the $400 \mathrm{rpm}$ 
and $200 \mathrm{~mm} / \mathrm{min}$ weld. The difference between the two rotation speeds and the hard 2024 versus the soft 2014 constitutive behaviour are investigated.

\subsection{Material Deformation Condition Plots}

To understand the softening behaviour and the differences between different rotation speeds and material constitutive models, plots were made of the material deformation 'condition'. This analysis identifies the temperature and flow stress of the material for each volume element in the model and superimposes it on the material constitutive behaviour (from Figure 4(b)). The material deformation condition plots in Figure 12 show contours of the probability density at a particular temperature and flow stress conditions. The concept is similar to a normal plot of probability density which gives the probability of a variable having a particular value. However, the plots shown in Figure 12 have two independent variables instead of one and the magnitude of the probability density is shown as a contour. If the contours in these plots are represented with a probability density function $f(T, \sigma)$ where $T$ is the temperature and $\sigma$ is the flow stress, then the probability that a region in the solution domain has a temperature between $T_{1}$ and $T_{2}$ and a flow stress between $\sigma_{1}$ and $\sigma_{2}$ is:

$$
P=\int_{\sigma_{1}}^{\sigma_{2}} \int_{T_{1}}^{T_{2}} f(T, \sigma) d T d \sigma
$$

Interesting differences are observed between the different plots. Using a higher rotation speed increases the temperature and results in more material being deformed at very high strainrates with a low flow strength. The remaining material which is at a lower temperature has a very low strain rate, and will in practice be undeformed (Finite Volume Method models never predict zero deformation since elastic properties of the material have been ignored.). At the lower rotation speed the deformation is more uniform with a larger amount of material being deformed with a high flow strength and strain-rate. Finally, comparing the hard 2024 material against the soft 2014 (i.e. (a,b) versus (c,d)) shows that the average strain-rate when welding with the harder material is lower. This is more noticeable at the low rotation speed. Note that the predicted material condition to some extent follows the constitutive law used, indicating the need for better hot flow experiments, particularly approaching the solidus.

\subsection{Rotational Flow Diagrams}

The velocity contours across a 2 dimensional slice underneath the tool shoulder are shown in Figure 13. One of the problems with using the Finite Volume Method to model the process is defining the boundary where the material starts to deform. The boundary where the velocity equals $0.005 \mathrm{~m} / \mathrm{s}$ was chosen as an indication of the limit of deformation and this is the last contour plotted in Figure 13. It is sufficient for comparing welding conditions and model types, but this is not strictly the true extent of the plastic deformation.

The conditions used in Figure 13(a)-(d) are identical to those used in the material deformation condition plots Figure 12(a)-(d). An additional model type (Figure 13(e)-(f)) is included in this analysis using a slip boundary condition at the shoulder. Because the analysis is only intended to be illustrative, slip was simulated by prescribing the velocity at the shoulder. The velocity was arbitrarily set equal to that of the pin where the pin and shoulder intersect, and then linearly reduced to zero at the periphery. The condition on the pin remained one of stick, with the material and pin velocities equal.

These diagrams illustrate several characteristics of the flow. Firstly, the lower rotation speed always results in a greater extent of deformation under the shoulder. This effect is more noticeable with the softer 2014 material (Figure 13(c)-(f)), where the deformation zone is 
large at $400 \mathrm{rpm}$. Using the slip boundary condition reduces the deformation under the shoulder when compared with the corresponding stick boundary condition, particularly when a rotation speed of $1600 \mathrm{rpm}$ is used.

\subsection{Discussion and Comparison with Weld Macrosections}

Both the rotational flow and deformation condition plot analyses show that high rotation speeds and hard materials cause high welding temperatures substantially within the softening regime, with the deformation concentrated near to the tool surface. In contrast, low rotation speeds and soft materials result in much less material entering the softening regime and a larger deformation size.

The reduction in deformation size with increasing rotation speed is counter-intuitive, because the greater surface velocity might be expected to cause more deformation. However the material deformation condition diagrams show how the material at higher temperature rapidly loses flow strength as the solidus is approached. Strengthening due to the increase in strainrate cannot compensate for the temperature softening - in the limit the material must eventually slip at the tool interface. Hence the deformation localises towards the tool surface. The opposite is also valid: for cooler welds where the flow strength is more uniform, so localisation of the deformation does not occur and the deformation size is larger.

The last two rotational flow diagrams (Figure 13(e)-(f)) are compared with the advancing side of the weld macrosections for the two rotation speeds in Figure 14. These models used the 2014 properties and a slip boundary condition at the shoulder. These parameters give the closest comparison with the weld macrosections. The comparisons are good, with the model predicting the smaller deformation region under the shoulder with the low rotation speed. The good comparison between the macrosections and the model that uses a slip boundary condition (particularly at $1600 \mathrm{rpm}$ ) suggest that this characteristic may exist in the real weld.

\section{Conclusions}

A model has been developed for predicting the heat generation and temperature field using the thermal and flow properties of the material being welded, the process conditions and the dimensions of the tool and workpiece. This heat generation is calculated with a 2 dimensional axisymmetric flow model which gave a very close prediction to that from a full 3 dimensional analysis. An analysis was done using a trial weld in 7449 aluminium alloy to determine the parameters important to heat generation. These included the constitutive behaviour of the material, and the contact radius of the shoulder. Although some difference in the heat generation was found with different constitutive behaviour, the change was small compared with changes in the shoulder contact radius.

This model was then applied directly to a series of friction stir welds in $3.2 \mathrm{~mm}$ thick 2024T351 and 4mm thick 6013-T6. The shoulder contact radius was calibrated with the 2024 welds which enabled a good correlation with the thermocouple data over a wide range of process conditions. The different axial loads (plunge) used for the experimental welds explains some of the discrepancy. Using the calibrated shoulder contact radius, the model was then applied to the 6013-T6 welds. The correlation with the experiments was good, indicating that the model can be used to predict the weld temperature of a new alloy if the flow and thermal properties are known. 
Two novel techniques were used to analyse the flow from the 2 dimensional axisymmetric flow model: material deformation condition plots and rotational flow diagrams. In this analysis high and low rotation speeds were compared as well as the effects of hard versus soft materials, stick versus slip boundary conditions at the shoulder, and different sizes of the softening regime in the constitutive model. The material deformation plots showed how higher rotation speeds caused a higher welding temperature, with more of the material being deformed in the 'Empirical Softening Regime' at a very high strain-rate and low flow strength. Using the harder constitutive response of 2024 material had a similar effect to the high rotation speed in that most of the material deformation was at a very high strain-rate and low flow strength.

These findings were reflected in the rotational flow diagrams, which showed that the deformation under the shoulder was greater at a lower rotation speed. This agreed with the flow indicated by the weld macrosections. Both high rotation speeds and harder materials caused more localised deformation near the tool surface. Finally, there appeared to be a better correlation between the weld macrosections and the rotational flow diagrams from the model when a slip boundary condition was used at the shoulder, particularly at the high rotation speed.

Although it appears that the boundary condition at the shoulder is likely to be slip, obtaining values for the surface shear stress is difficult because the limiting interfacial shear stress will be sensitive to the temperature, the slip velocity and the normal stress. The alternative approach adopted here of using a stick boundary condition with an artificially small shoulder contact radius may be less physically realistic, but gives a much simpler model for predicting the heat generation which works well.

\section{Acknowledgements}

The authors would like to thank Airbus, the Isaac Newton Trust and GKSS for funding this work. Thanks also go to Alcan for supplying the flow stress data for 7449 and 6056 aluminium alloys. Finally, the help of Daniela Lohwasser from Airbus Germany, Stewart Williams from Cranfield University, Jorge Dos Santos from GKSS and Mike Poad from Airbus UK was greatly appreciated.

\section{References}

1. D. Lohwasser: Proc. $4^{\text {th }}$ Int. Symp. on 'Friction Stir Welding', Park City, Utah, May 2003, TWI Ltd.

2. R. Zettler, S. Lomolino, J. F. dos Santos, T. Donath, F. Beckmann, T. Lippman, D. Lohwasser: Proc. 5th Int. Symp. on 'Friction Stir Welding', Metz, France, September 2004, TWI Ltd.

3. H. R. Shercliff, and P. A. Colegrove: in 'Mathematical Modelling of Weld Phenomena 6', (ed. H. Cerjak, and H. K. H. D. Bhadeshia), 927-974; 2002, London, Maney Publishing.

4. M. J. Russell, and H. R. Shercliff: Proc. 7th Int. Conf. on 'Joints in Aluminium' INALCO '98', Cambridge, UK, April 1998, Abington Publishing, 197-207.

5. M. J. Russell, and H. R. Shercliff: Proc. 1st Int. Symp. on 'Friction Stir Welding', Thousand Oaks, California, USA, June 1999, TWI Ltd.

6. J. C. McClure, Z. Feng, T. Tang, J. E. Gould, and L. E. Murr: Proc. 5th Int. Conf. on 'Trends in Welding Research', Pine Mountain, Georgia, June 1998, ASM International, 590-594. 
7. J. E. Gould, and Z. Feng: Journal of Materials Processing \& Manufacturing Science, 1998, 7(2), 185-194.

8. R. W. Fonda, and S. G. Lambrakos: Sci. Technol. Weld. Joining., 2002, 7(3), 177-181.

9. M. Song, and R. Kovacevic: Trans. of NAMRI/SME, 2002, XXX, 565-572.

10. M. Song, R. Kovacevic, J. Ouyang, and M. Valant: Proc. 6th Int. Conf. on 'Trends in Welding Research', Phoenix, Arizona, April 2002, ASM International, 212-217.

11. M. Song and R. Kovacevic: Proc. Instn Mech. Engrs. Part B: Journal of Engineering Manufacture, 2004, 218, 17-33.

12. M. Song, and R. Kovacevic: Proc. Instn Mech. Engrs. Part B: Journal of Engineering Manufacture, 2003, 217, 73-85.

13. Y. J. Chao, and X. Qi: Journal of Materials Processing \& Manufacturing Science, 1998, $7(2), 163-172$.

14. Y. J. Chao, and X. Qi: Proc. 1st Int. Symp. on 'Friction Stir Welding', Thousand Oaks, CA, June 1999, TWI Ltd.

15. P. Colegrove, M. Painter, D. Graham, and T. Miller: Proc. 2nd Int. Symp. on 'Friction Stir Welding', Gothenburg, Sweden, 2000, TWI Ltd.

16. P. Colegrove: Proc. of IIW Asian Pacific Welding Congress, Melbourne, Australia, 2000, Welding Technology Institute of Australia, Vol.1, Paper 15.

17. P. A. Colegrove and H. R. Shercliff: Sci. Technol. Weld. Joining, 2003, 8, (5), 360-368.

18. K. Lindner, Z. Khandkar, J. Khan, W. Tang, and A. P. Reynolds: Proc. 4th Int. Symp. on 'Friction Stir Welding', Park City, Utah, May 2003, TWI Ltd.

19. Q-Y Shi, T. Dickerson, and H. R. Shercliff: Proc. 4th Int. Symp. on 'Friction Stir Welding', Park City, Utah, May 2003, TWI Ltd.

20. M. Z. H. Khandkar, and J. A. Khan: J. Materials Processing \& Manufacturing Sci., 2001, 10(2), 91-105.

21. M. Z. H. Khandkar, J. A. Khan, and A. P. Reynolds: Proc. 6th Int. Conf. on 'Trends in Welding Research', Phoenix, Arizona, April 2002, ASM International, 218-223.

22. M. Z. H. Khandkar, J. A. Khan, and A. P. Reynolds: Sci. Technol. Weld. Joining, 2003, 8(3), 166-174.

23. T. De Vuyst, L. D’Avise, A. Simar, B. de Meester, S. Pierret: Proc. 5th Int. Symp. on 'Friction Stir Welding', Metz, France, September 2004, TWI Ltd.

24. R. W. McCune, H. Ou, C. G. Armstrong and M. Price: Proc. 5th Int. Symp. on 'Friction Stir Welding', Metz, France, September 2004, TWI Ltd.

25. Ch. Desrayaud, P. Heurtier, D. Allehaux, and F. Montheillet: Proc. 5th Int. Symp. on 'Friction Stir Welding', Metz, France, September 2004, TWI Ltd.

26. C. M. Chen, and R. Kovacevic: Proc. 4th Int. Symp. on 'Friction Stir Welding', Park City, Utah, May 2003, TWI Ltd.

27. C. M. Chen and R. Kovacevic: International Journal of Machine Tools and Manufacture, 2003, 43, 1319-1326.

28. C.M. Chen and R. Kovacevic: Proc. Instn Mech. Engrs. Part C: Journal of Mechanical Engineering Science, 2004, 218, 509-519.

29. Q-Y Shi, T. Dickerson, and H. R. Shercliff: Proc. 6th Int. Conf. on 'Trends in Welding Research', Phoenix, Arizona, April 2002, ASM International, 247-252.

30. P. Heurtier, M. J. Jones, C. Desrayaud, J. H. Driver, and F. Montheillet: in 'Materials Science Forum', Vols. 426-432, 2927-2932; 2003, Switzerland, Trans Tech Publications.

31. W-S Chang, H-S Bang, S-B Jung, Y-M Yeon, H-J Kim, and W-B Lee: in 'Materials Science Forum', Vols. 426-432, 2953-2958; 2003, Switzerland, Trans Tech Publications.

32. D. Lawrjaniec, A. Abisror, C. Decker, M. Koçak, and J. Dos Santos: in 'Materials Science Forum', Vols. 426-432, 2993-2998; 2003, Switzerland, Trans Tech Publications. 
33. Ø. Frigaard, Ø. Grong, and O. T. Midling: Met. and Mater Trans. A, 2001, 32A(5), 11891200.

34. Ø. Frigaard, Ø. Grong, B. Bjørneklett, and O. T. Midling: Proc. 1st Int. Symp. on 'Friction Stir Welding', Thousand Oaks, CA, June 1999, TWI Ltd.

35. Ø. Frigaard, Ø. Grong, and O. T. Midling: Proc. 7th Int. Conf. on 'Joints in Aluminium' INALCO '98', Cambridge, UK, April 1998, Abington Publishing, 208-218.

36. P. Vilaca, L. Quintino, J. F. dos Santos: Journal of Materials Processing Technology, 2005, 169(3), 452-465.

37. S. Xu, and X. Deng: Proc. 4th Int. Symp. on 'Friction Stir Welding', Park City, Utah, May 2003, TWI Ltd.

38. P. Dong, F. Lu, J. K. Hong, and Z. Cao: Proc. 1st Int. Symp. on 'Friction Stir Welding', Thousand Oaks, CA, June 1999, TWI Ltd.

39. P. Dong, F. Lu, J. K. Hong, and Z. Cao: Sci. Technol. Weld. Joining., 2001, 6(5), 281-287.

40. P. Ulysse: International Journal of Machine Tools \& Manufacture, 2002, 42, 1549-1557.

41. L. D. Oosterkamp, O. J. Emmerhoff, and O. T. Midling: in 'Recent Advances in Welding Simulation', 79-88; 2000, London, IMechE.

42. R. L. Goetz, and K. V. Jata: in 'Friction Stir Welding and Processing', (Ed. K.V. Jata et al.) 35-42; 2001, Warrendale, PA, TMS.

43. A. Askari, S. Silling, B. London, and M. Mahoney: in 'Friction Stir Welding and Processing', (Ed. K.V. Jata et al.) 43-54; 2001, Warrendale, PA, TMS.

44. A. Askari: Proc. of 'FSW Flow Visualisation and Modelling Seminar', Geesthacht, Germany, February 2003, GKSS.

45. L. Fourment, S. Guerdoux, M. Miles and T. Nelson: Proc. 5th Int. Symp. on 'Friction Stir Welding', Metz, France, September 2004, TWI Ltd.

46. H. Schmidt and J. Hattel: Proc. 5th Int. Symp. on 'Friction Stir Welding', Metz, France, September 2004, TWI Ltd.

47. H. Schmidt and J. Hattel: Modelling Simul. Mater. Sci. Eng., 2005, 13, 77-93.

48. P. A. Colegrove and H. R. Shercliff: Sci. Technol. Weld. Joining, 2004, 9, (4), 352-361.

49. P. A. Colegrove and H. R. Shercliff: Journal of Materials Processing Technology, 2005, 169, 320-327.

50. F. Palm, U. Henneböhle and V. Erofeev: Proc. 5th Int. Symp. on 'Friction Stir Welding', Metz, France, September 2004, TWI Ltd.

51. P. A. Colegrove and H. R. Shercliff: Sci. Technol. Weld. Joining, 2004, 9(6), 483-492.

52. P. A. Colegrove and H. R. Shercliff: Sci. Technol. Weld. Joining, 2004, 9(4), 345-351.

53. T. U. Seidel, and A.P. Reynolds: Sci. Technol. Weld. Joining, 2003, 8(3), 175-183.

54. N. Kamp and J. D. Robson: TMS Letters, 2005, 2(1), 9.

55. FLUENT, Release 6.1.22, Fluent Incorporated, 2004, Lebanon, NH.

56. C. M. Sellars, and W. J. Mc. G. Tegart: Int. Met Rev, 1972, 17, 1-24.

57. T. Sheppard and D. Wright: Met. Technol., 1979, 6, 215-223.

58. T. Sheppard and A. Jackson: Materials Science and Technology, 1997, 13, 203-209.

59. H. Valberg and T. Malvik: Int. J. of Materials and Product Technology, 1994, 9(4/5/6), 428-463.

60. J. Yan, M. A. Sutton, and A. P. Reynolds: Sci. Technol. Weld. Joining, 2005, 10(6), $725-$ 736.

61. T. Long, T. U. Seidel, W. Tang, and A. P. Reynolds: in 'Hot Deformation of Aluminium Alloys III', (ed. Z. Jin et al.), 2003, Warrendale, PA, TMS.

62. P. A. Colegrove and H. R. Shercliff: 'CFD Modelling of the Friction Stir Welding of Thick Plate 7449 Aluminium Alloy', Sci. Technol. Weld. Joining (in press).

63. W. Tang, X. Guo, J. C. McClure, L. E. Murr, and A. Nunes: Journal of Materials Processing \& Manufacturing Science, 1998, 7(2), 163-172. 
64. J. R. Davis, 'ASM Speciality Handbook: Aluminium and Aluminium Alloys', 654; 1993, ASM International.

65. http:://www.matweb.com

66. K. C. Mills: 'Recommended values of thermophysical properties for commercial alloys', 2002, Cambridge, UK, Woodhead Publishing Ltd. 
Table 1 Details of the constitutive models used to describe the different materials.

\begin{tabular}{|l|c|c|c|c|}
\hline Material & $\mathbf{7 4 4 9}$ & $\mathbf{2 0 2 4}$ & $\mathbf{2 0 1 4}$ & $\mathbf{6 0 5 6}$ \\
\hline Representative of? & $\mathbf{7 4 4 9}$ & $\mathbf{2 0 2 4}$ & $\mathbf{2 0 2 4}$ & $\mathbf{6 0 1 3}$ \\
\hline $\mathrm{A}(/ \mathrm{s})$ & $1.26 \times 10^{8}$ & $3.25 \times 10^{8}$ & $4.47 \times 10^{13}$ & $2.47 \times 10^{11}$ \\
\hline $\mathrm{Q}(\mathrm{J} / \mathrm{mol})$ & 134158.4 & 148,880 & 176,867 & $1.81 \mathrm{E}+05$ \\
\hline$n$ & 3.24644 & 4.27 & 5.86 & 2.9914 \\
\hline$\alpha(/ \mathrm{MPa})$ & 0.03055 & 0.016 & 0.0118 & 0.045 \\
\hline Solidus Temperature $\left({ }^{\circ} \mathrm{C}\right)$ & 500 & 502 & 502 & 579 \\
\hline & $\begin{array}{c}\text { Alcan } \\
\text { Experiments }\end{array}$ & $\begin{array}{c}\text { Sheppard and }_{\text {Jackson }^{58}} \\
\text { Data Source }\end{array}$ & $\begin{array}{c}\text { Sheppard and } \\
\text { Jackson }^{58}\end{array}$ & $\begin{array}{c}\text { Alcan } \\
\text { Experiments }\end{array}$ \\
\hline
\end{tabular}

Table 2 Weld matrix for $3.2 \mathrm{~mm}$ thick 2024-T351 welds. The vertical load (force in the $z$ direction in $\mathrm{kN}$ ) used for each weld is shown in each case.

\begin{tabular}{|c|c|c|c|c|c|c|c|c|c|}
\hline & \multicolumn{8}{|c|}{ Welding Speed (mm/min) } \\
\hline & & 50 & 100 & 150 & 200 & 300 & 400 & 600 & 800 \\
\hline \multirow{4}{*}{ 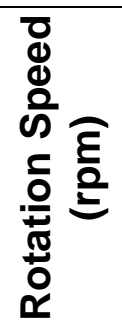 } & 1600 & & & & 8.93 & & 9.06 & & 9.08 \\
\hline & 1200 & & & 5.82 & & 7.69 & & 9.07 & \\
\hline & 800 & & 5.66 & & $\begin{array}{c}5.77 \\
\& 7.70\end{array}$ & & 8.21 & & \\
\hline & 400 & 5.62 & 8.03 & & 8.58 & & 11.57 & & \\
\hline
\end{tabular}

Table 3 Values of the key boundary conditions used for the thermal model of 2024 and 6013 aluminium alloys.

\begin{tabular}{|l|l|}
\hline$R_{l}\left(\mathrm{~mm}^{2} \mathrm{~K} / \mathrm{W}\right)$ & 40 \\
\hline$R_{2}\left(\mathrm{~mm}^{2} \mathrm{~K} / \mathrm{W}\right)$ & 5000 \\
\hline$h_{b}\left(\mathrm{~W} / \mathrm{m}^{2} \mathrm{~K}\right)$ & 1000 \\
\hline$h_{v}\left(\mathrm{~W} / \mathrm{m}^{2} \mathrm{~K}\right)$ & 100 \\
\hline
\end{tabular}




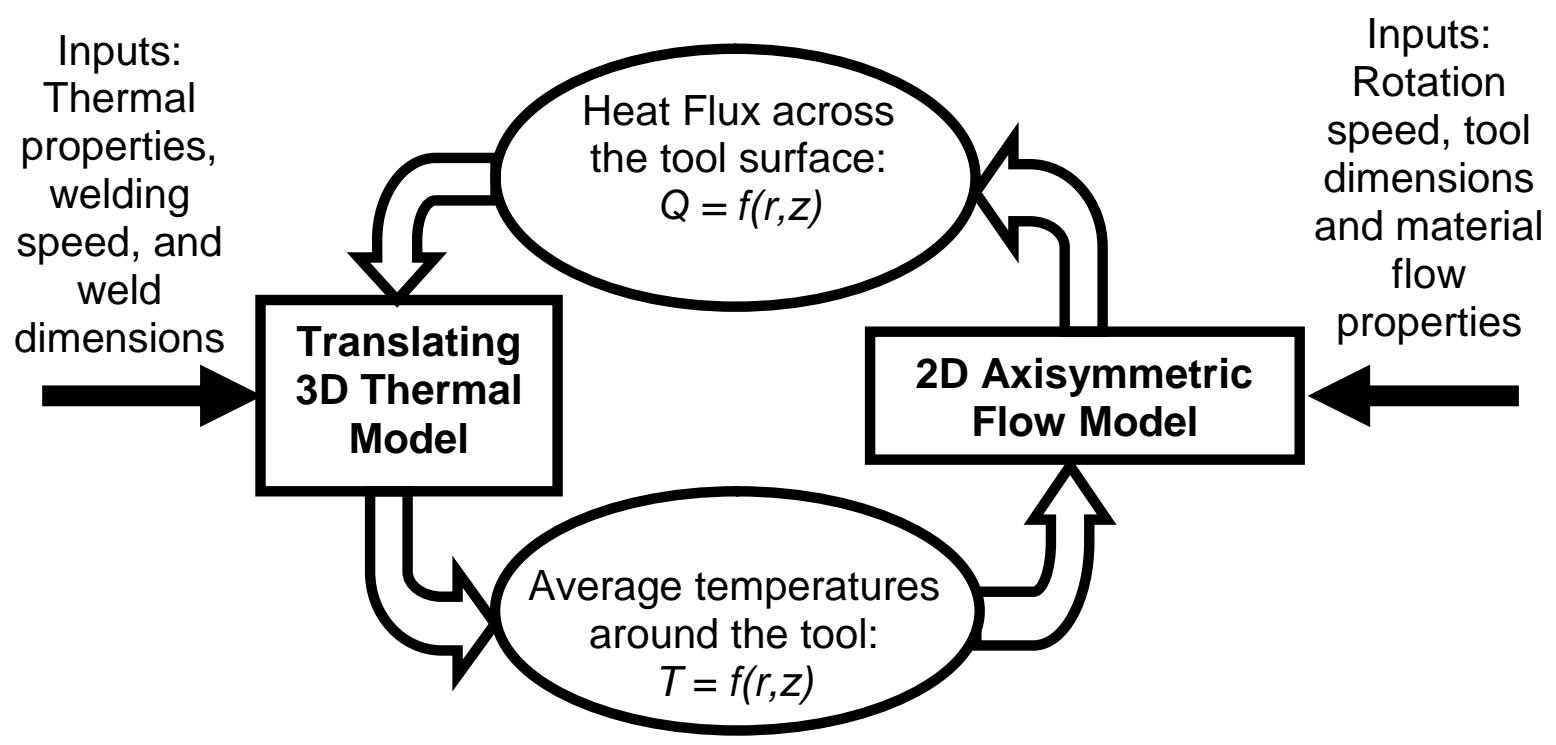

Figure 1 Flow diagram showing how the 2 dimensional axisymmetric flow model is coupled to the thermal model.

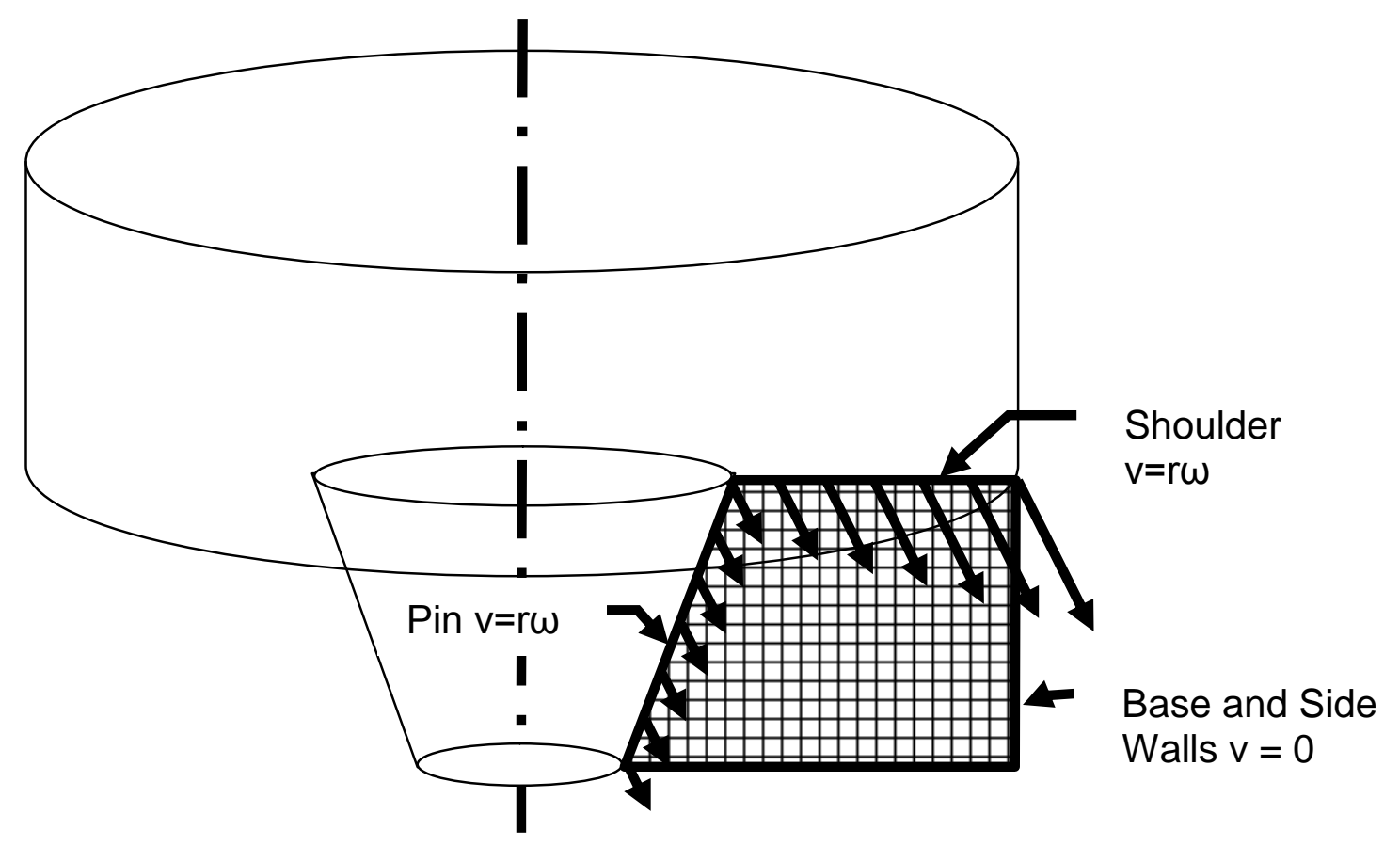

Figure 2 Description of the 2 dimensional axisymmetric flow model. 


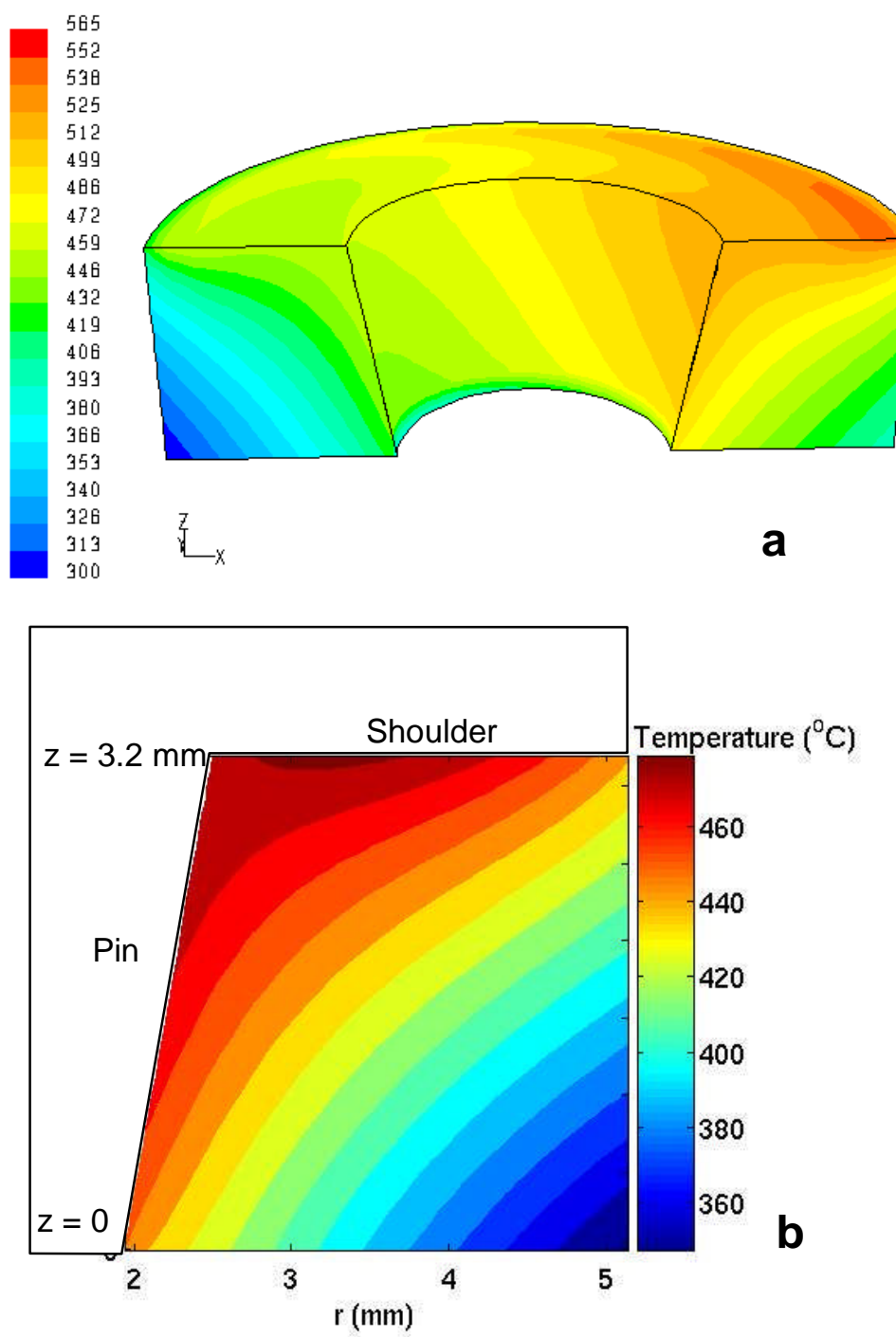

Figure 3 (a) Temperature contours in the region under the shoulder in the translating thermal model and (b) the corresponding average temperature imposed on the 2 dimensional axisymmetric flow model. Note that the two figures use different temperature scales. 

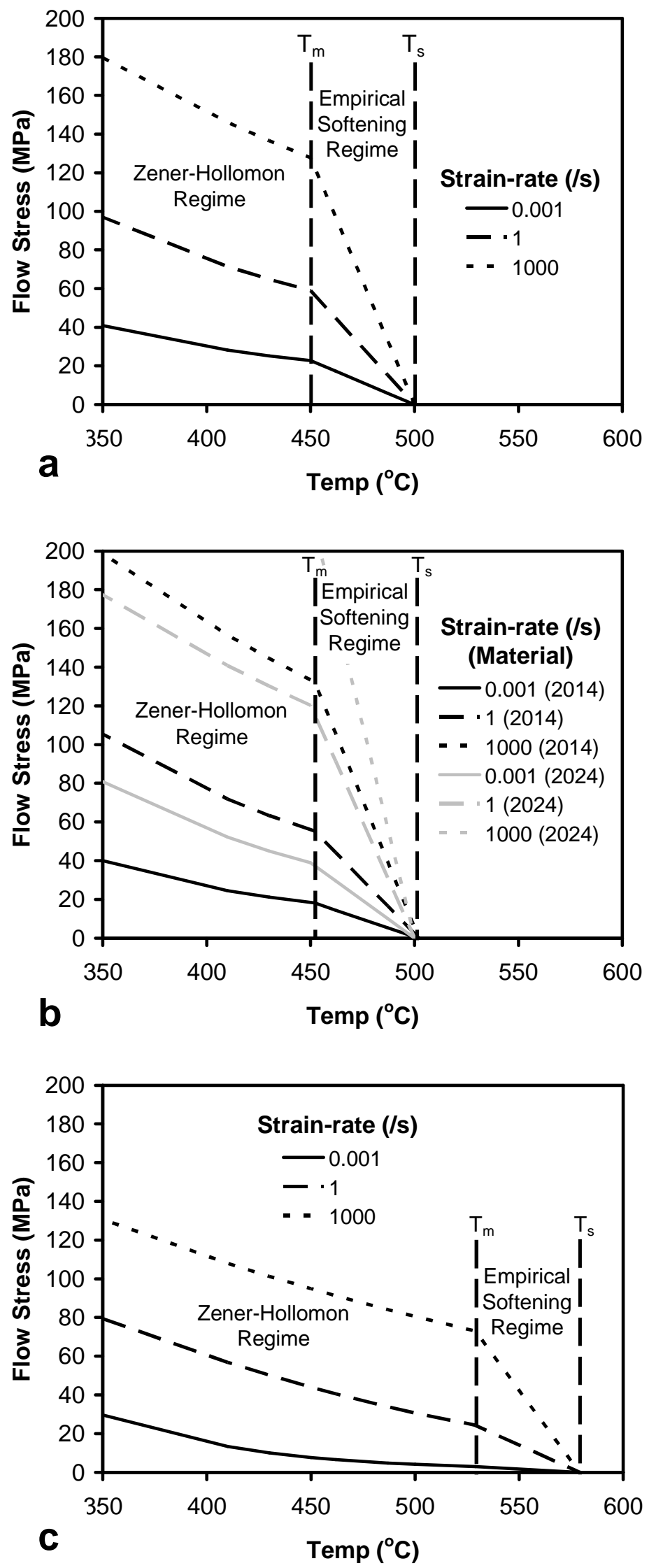

Figure 4 Constitutive behaviour of (a) 7449 (b) 2014 and 2024 and (c) 6056 aluminium alloys. 


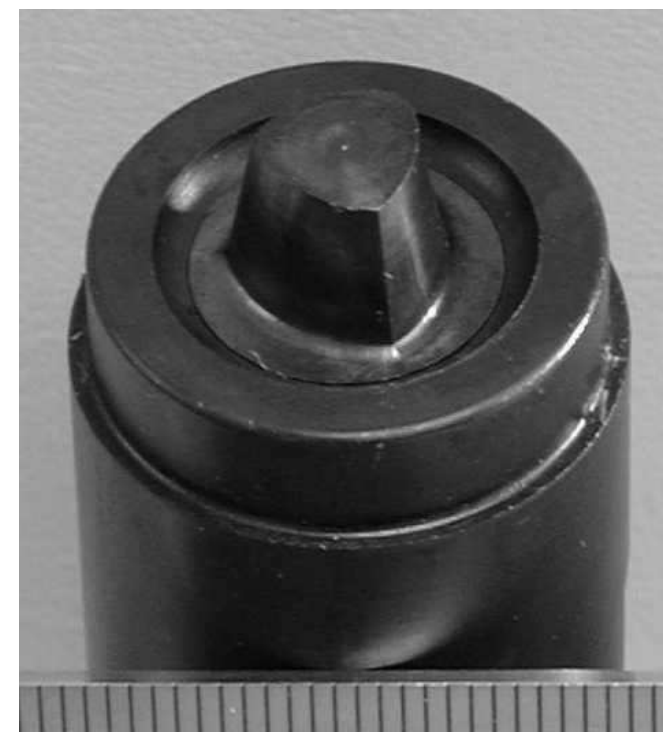

Figure 5 The Trivex friction stir welding tool ${ }^{52}$. 

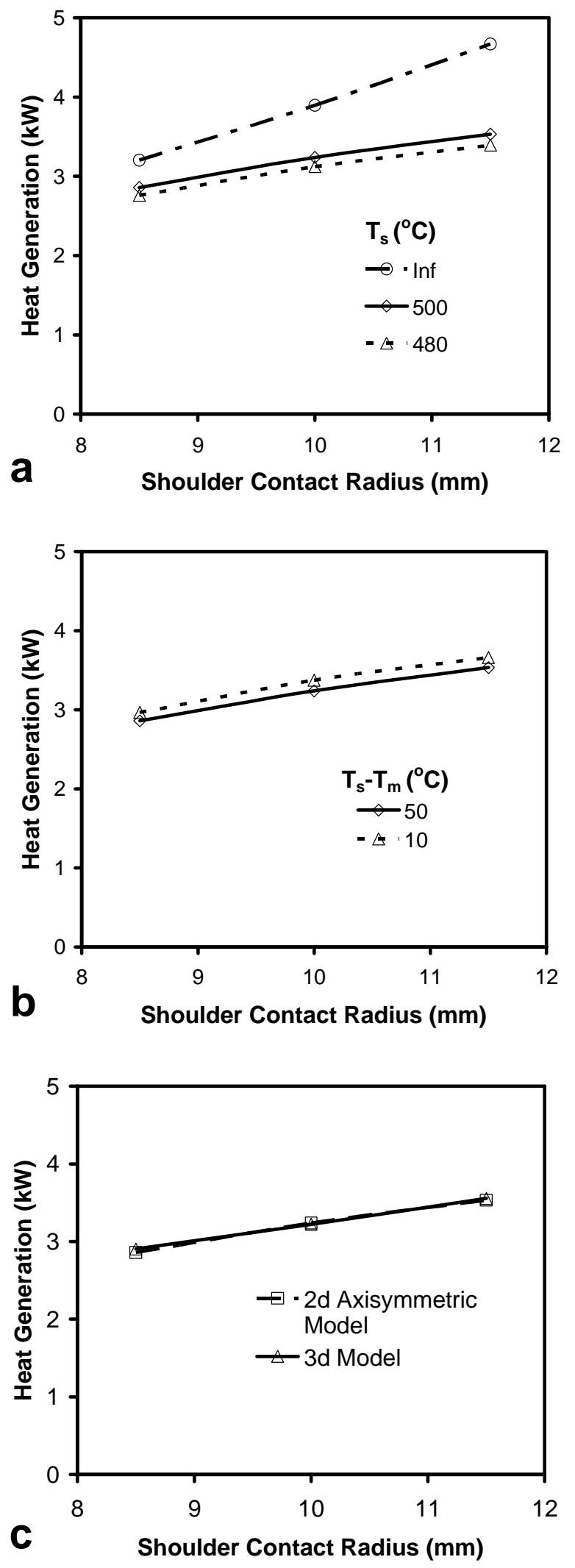

Figure 6 Variation in the heat generation for $6.35 \mathrm{~mm} 7449$ aluminium alloy with the shoulder contact radius and (a) the solidus temperature; (b) the size of the softening regime and (c) comparison between the simplified model and a fully coupled $3 \mathrm{~d}$ flow model. 


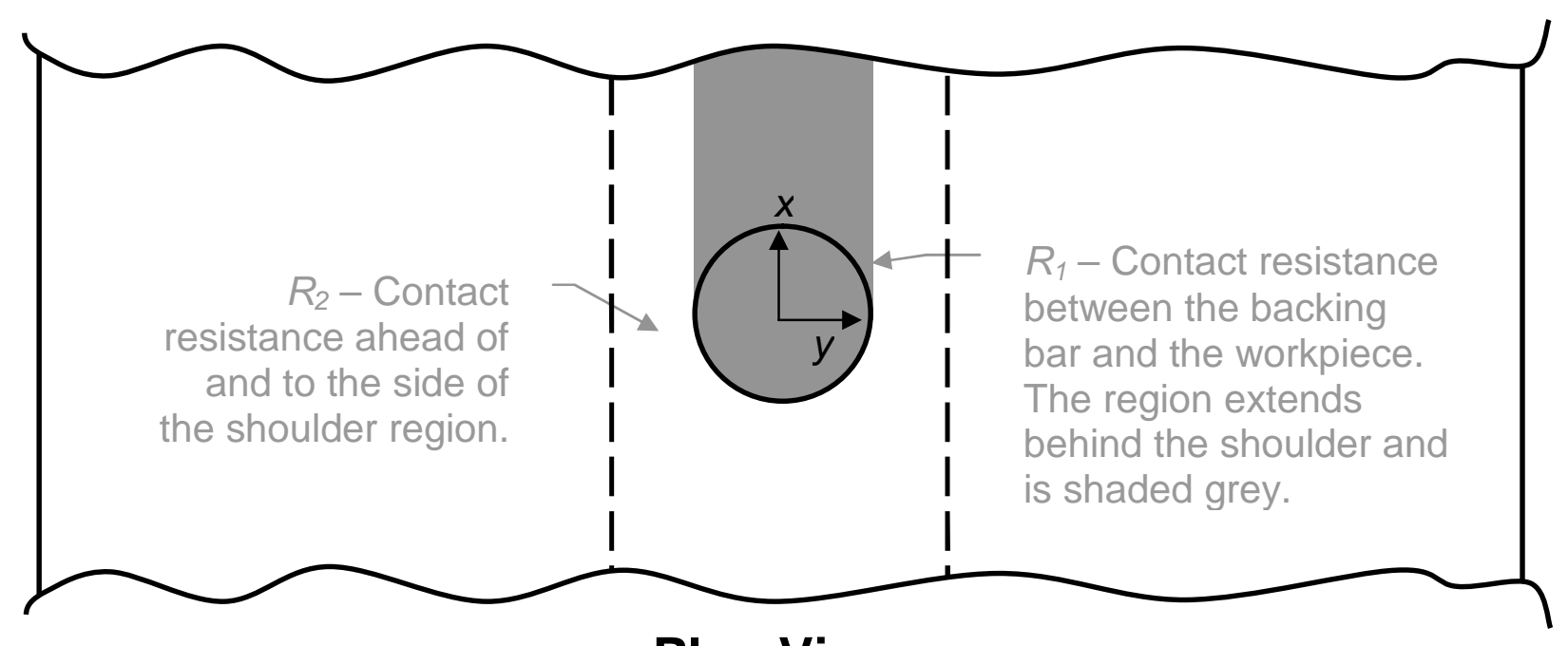

\section{Plan View}

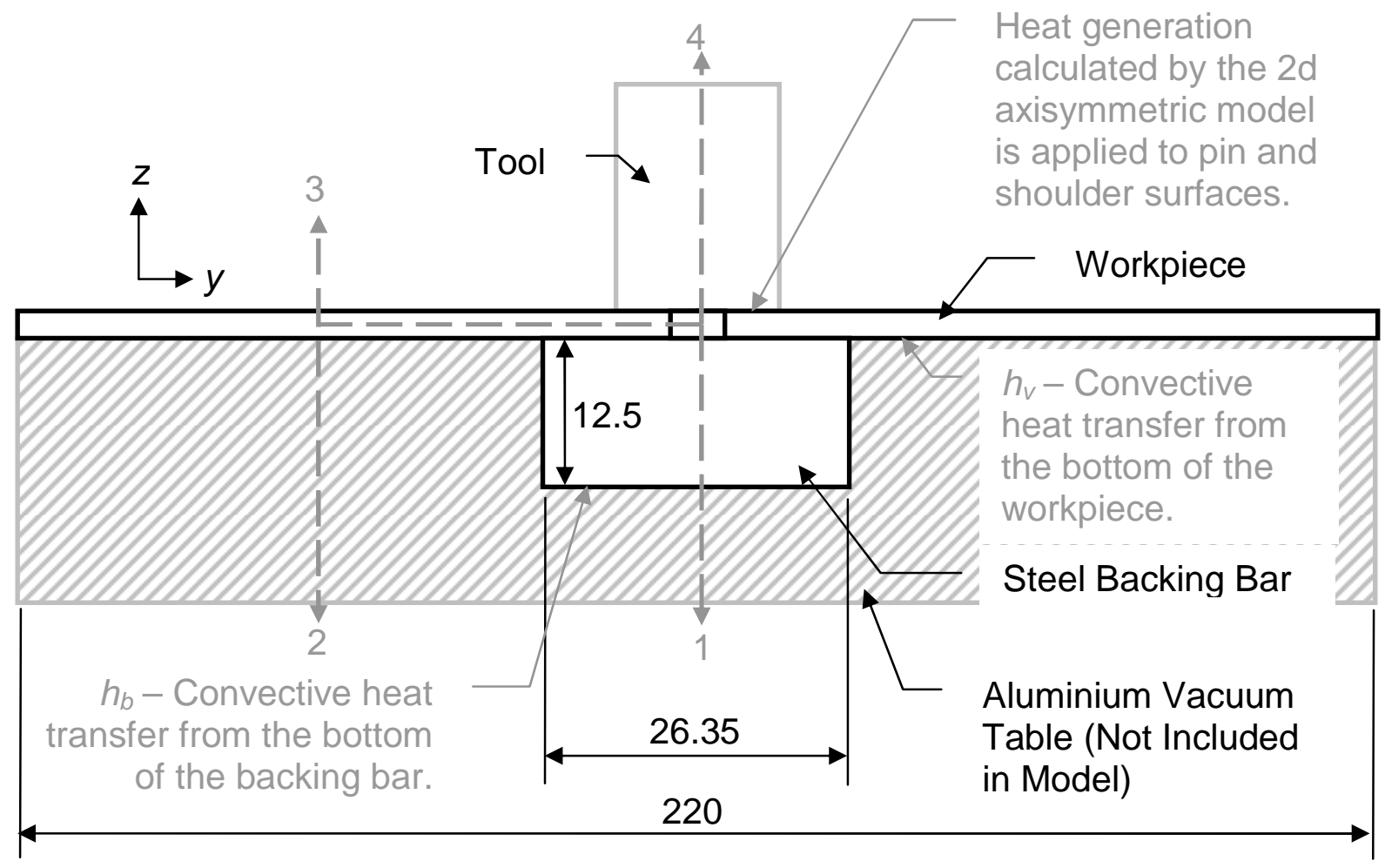

Figure 7 Diagram showing the welding layout for 2024 and 6013 welds, and the thermal boundary conditions used for the models (which are shown in grey). 


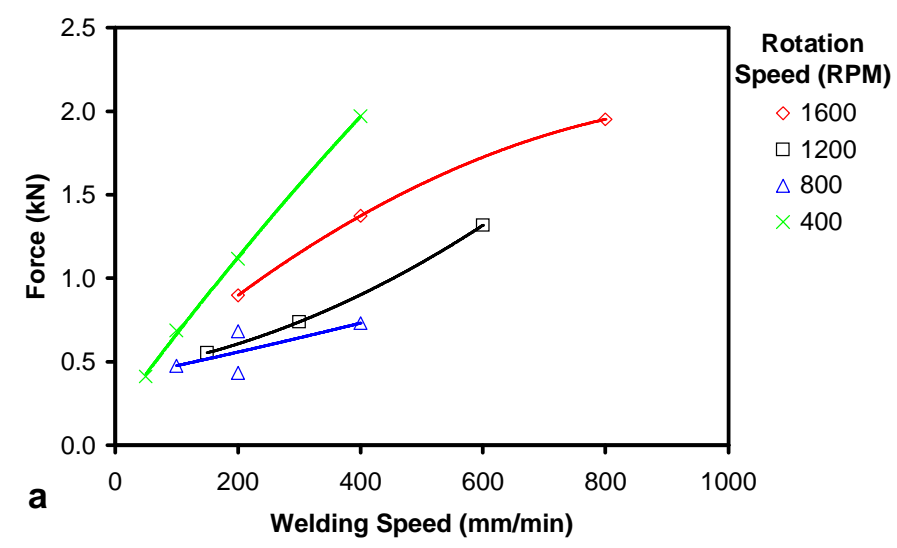

Figure 8 Measured traversing force versus welding and rotation speed for the $3.2 \mathrm{~mm}$ thick 2024-T351 welds.

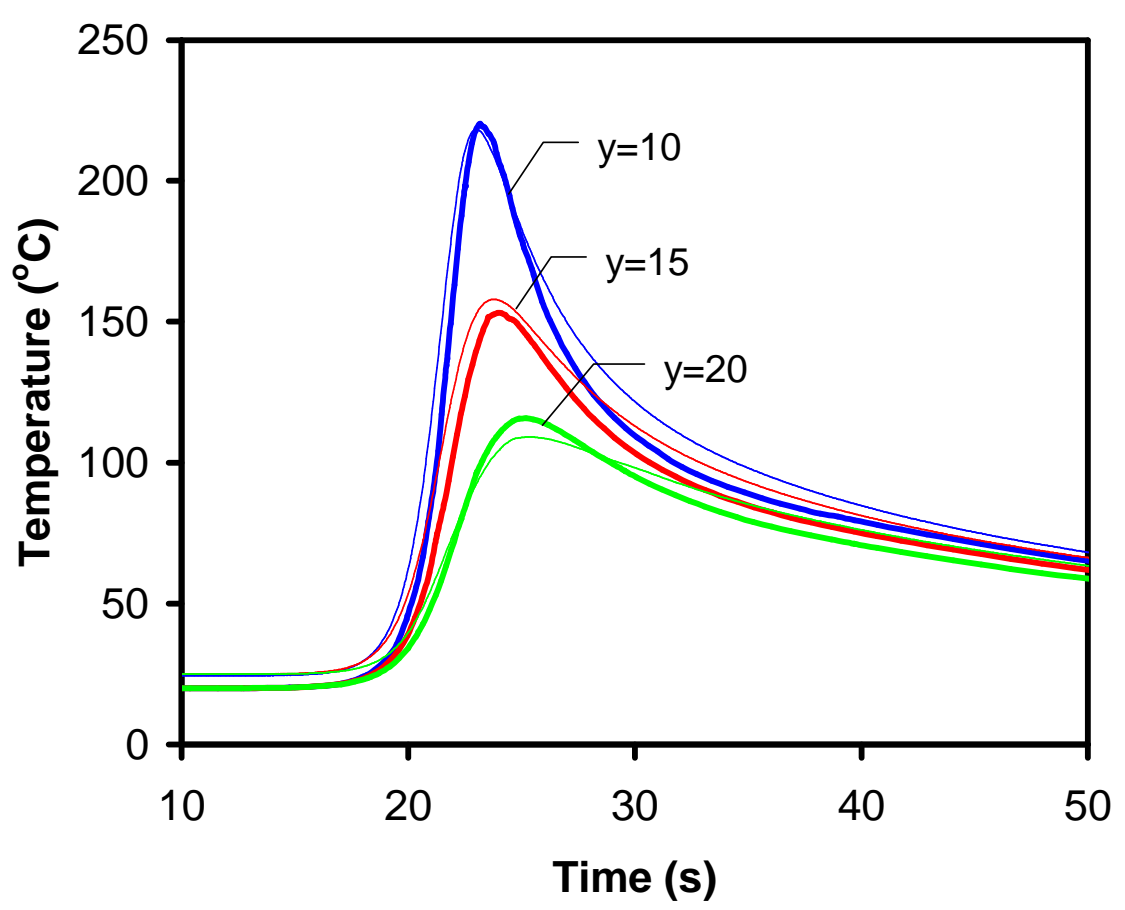

Figure 9 Comparison between the model and experimental results from the advancing side for a 2024 weld that used a rotation speed of $800 \mathrm{rpm}$ and a welding speed of $400 \mathrm{~mm} / \mathrm{min}$. Bold lines are model results and thin lines are experimental results at a depth of $1 \mathrm{~mm}$. 


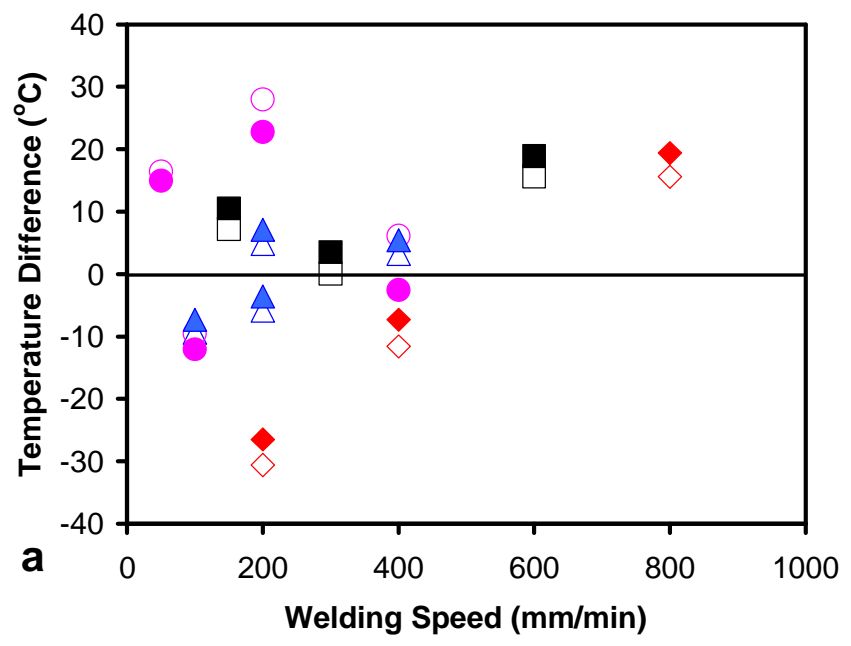

\section{Rotation \\ Speed (RPM) \\ (Material)}

$\diamond 1600$ (2024)

$\square 1200$ (2024)

$\triangle 800$ (2024)

$\bigcirc 400$ (2024)

- 1600 (2014)

1200 (2014)

$\triangle 800$ (2014)

- 400 (2014)

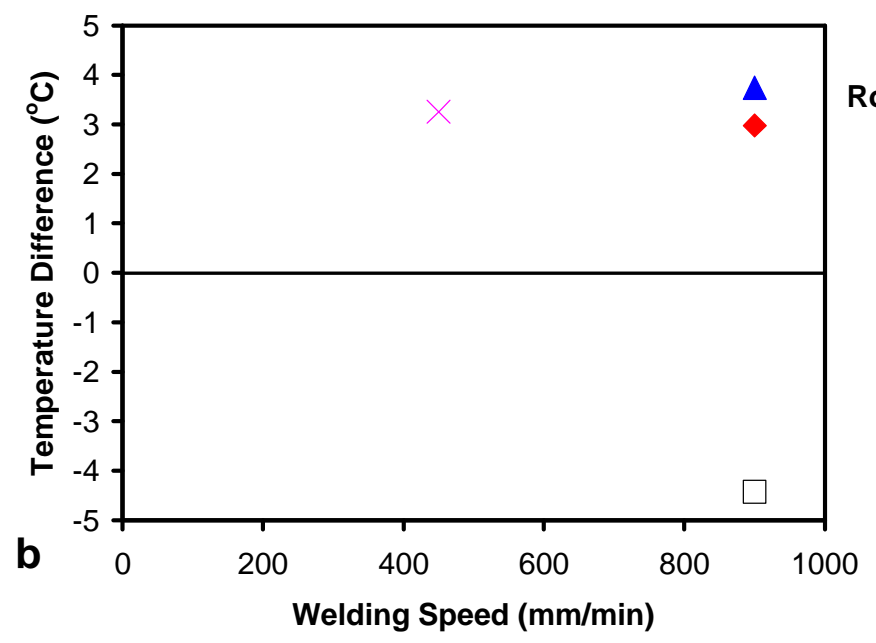

Rotation Speed

(RPM)

- 1700

$\square 1400$

\ 1200

$\times 900$

Figure 10 Peak temperature difference between the model and thermocouple measurements $10 \mathrm{~mm}$ from the centre of the tool for (a) 2024 and 2014 and (b) 6013 material properties. 

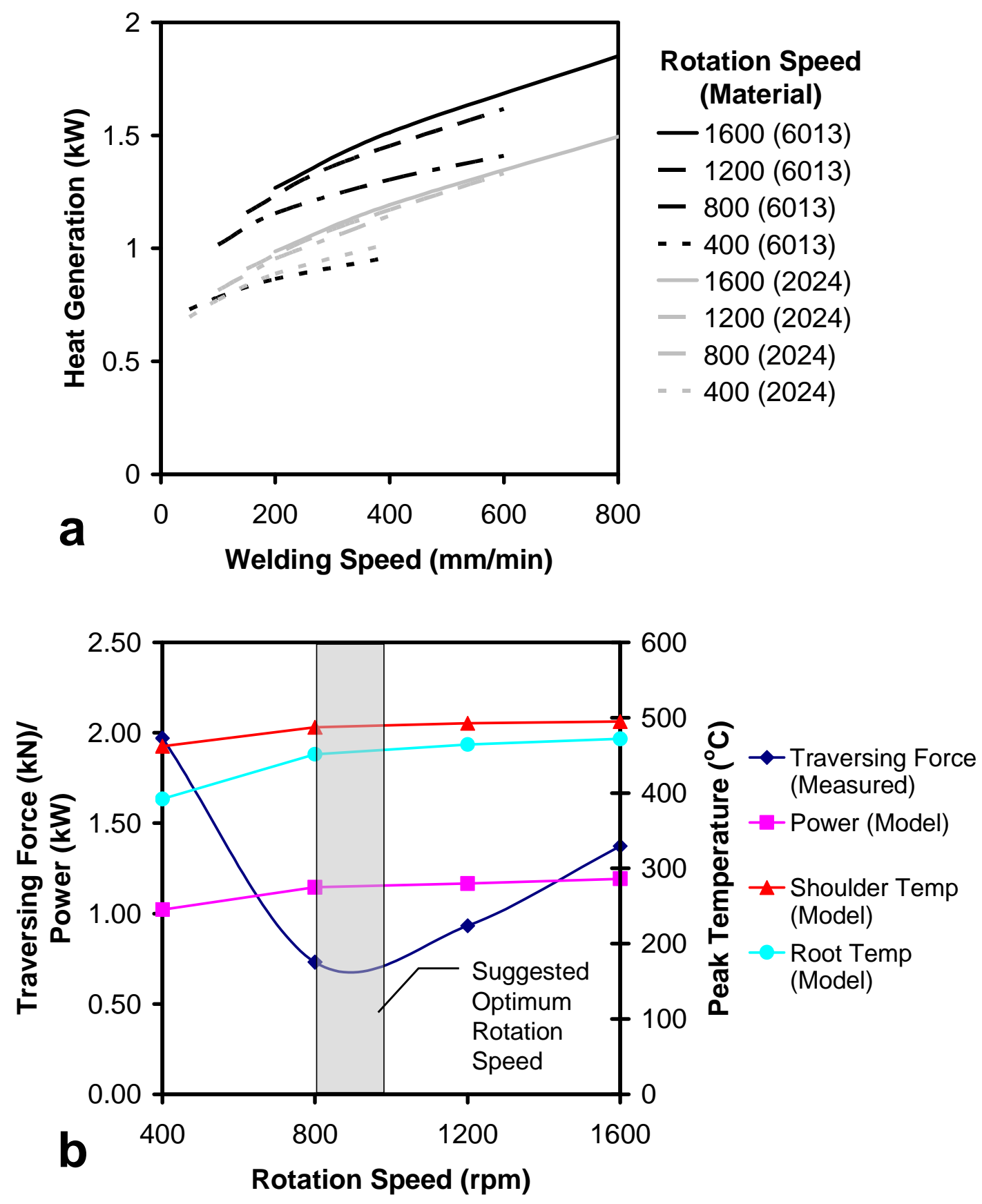

Figure 11 (a) Comparison of the heat generation between $3.2 \mathrm{~mm}$ thick 2024-T351 and 6013T6 welds and (b) plot of the heat generation, traversing force and peak temperatures at the shoulder and root of the weld as a function of the rotation speed for a welding speed of 400 $\mathrm{mm} / \mathrm{min}$ using 2024 aluminium alloy. 

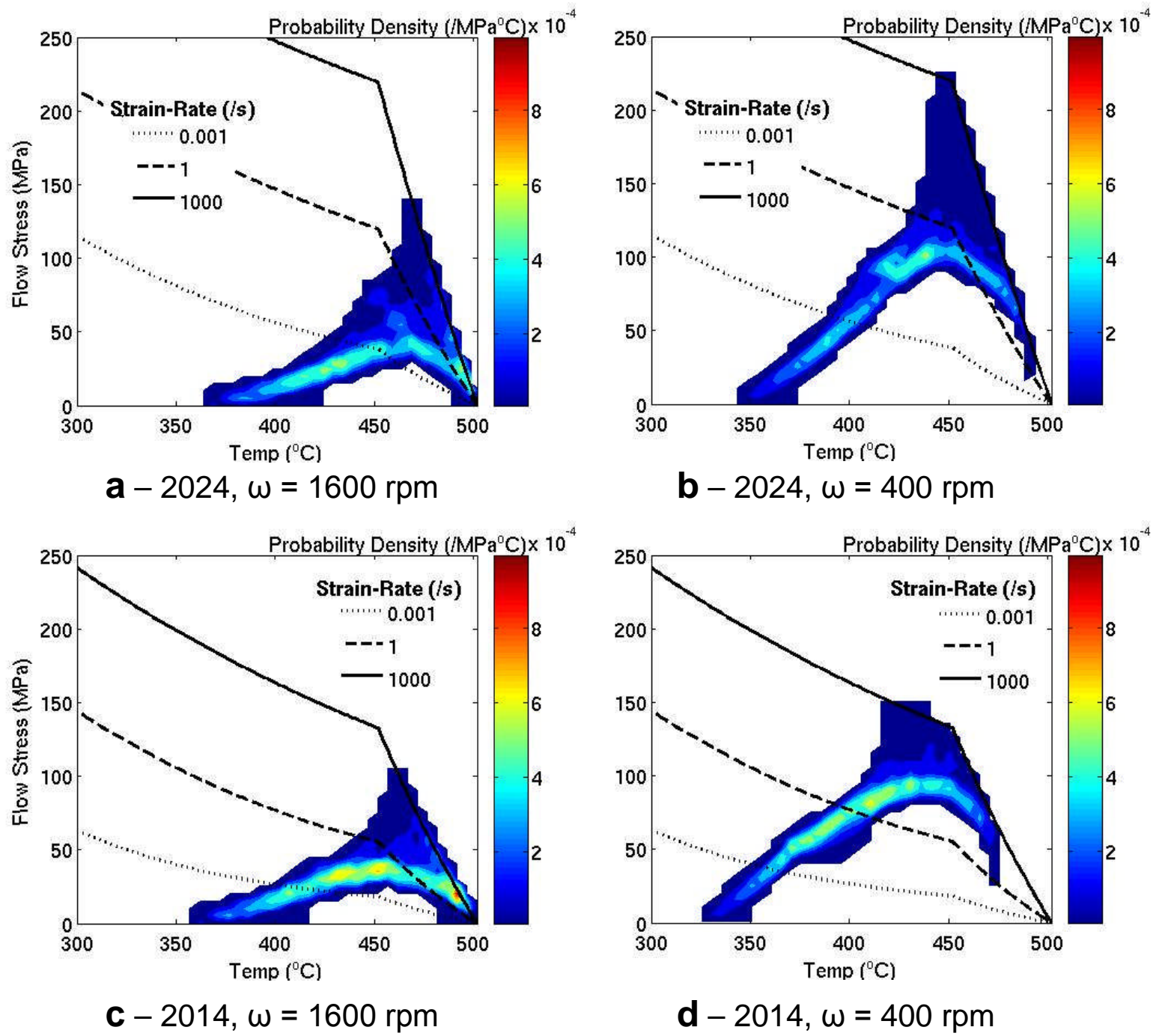

Figure 12 Material deformation condition plots from the 2 dimensional axisymmetric model using the constitutive behaviour for 2024 and 2014. All models use a welding speed of $200 \mathrm{~mm} / \mathrm{min}$. The material, and rotation speed are indicated for each of the cases (a-d). 

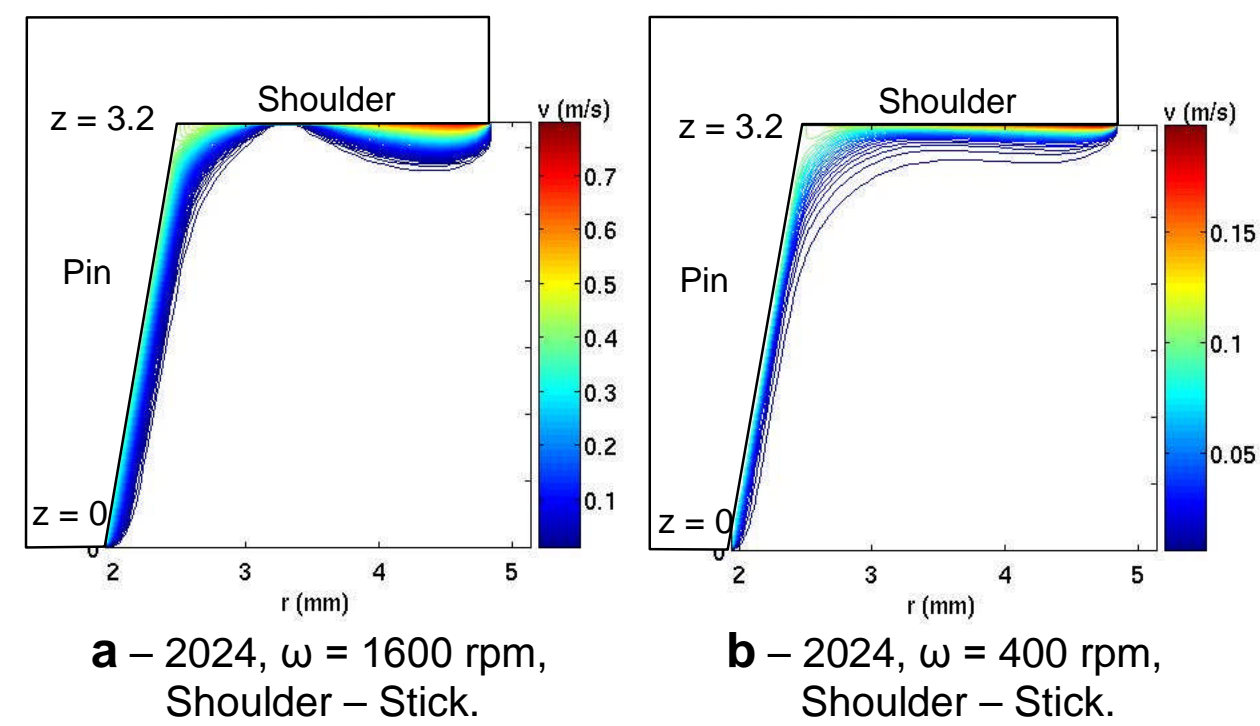

b $-2024, \omega=400$ rpm, Shoulder - Stick.

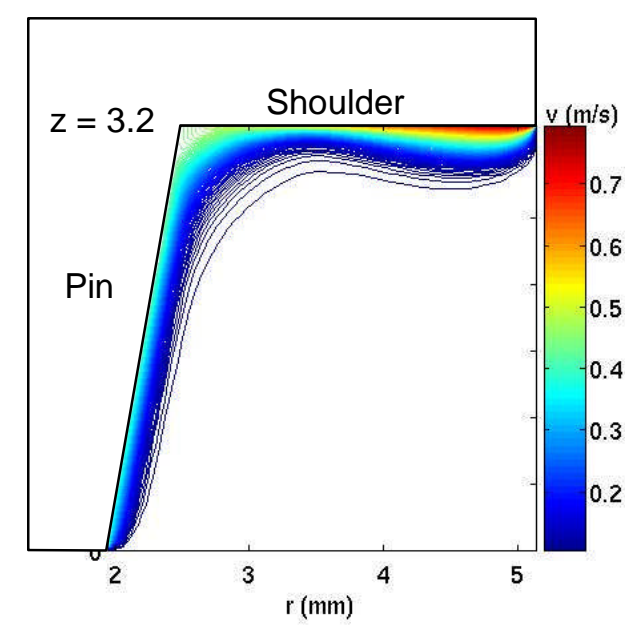

$$
\begin{gathered}
\text { C }-2014, \omega=1600 \text { rpm, } \\
\text { Shoulder - Stick. }
\end{gathered}
$$

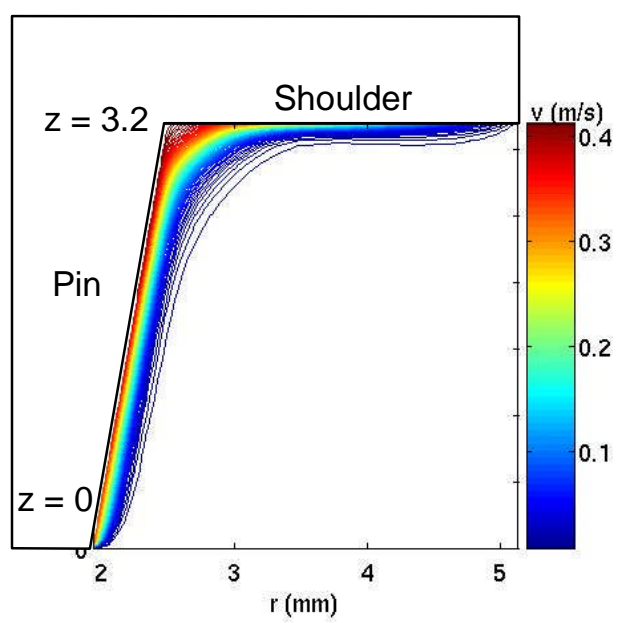

$$
\begin{gathered}
\text { e }-2014, \omega=1600 \text { rpm, } \\
\text { Shoulder - Slip. }
\end{gathered}
$$

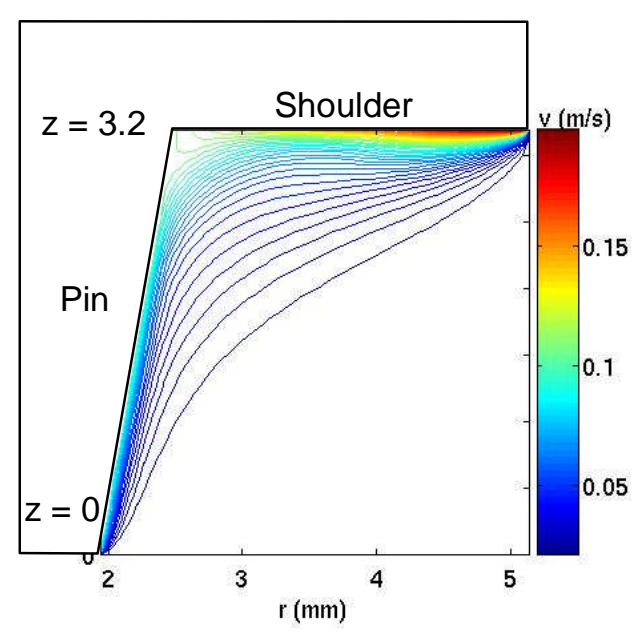

$$
\begin{gathered}
\text { d }-2014, \omega=400 \text { rpm, } \\
\text { Shoulder - Stick. }
\end{gathered}
$$

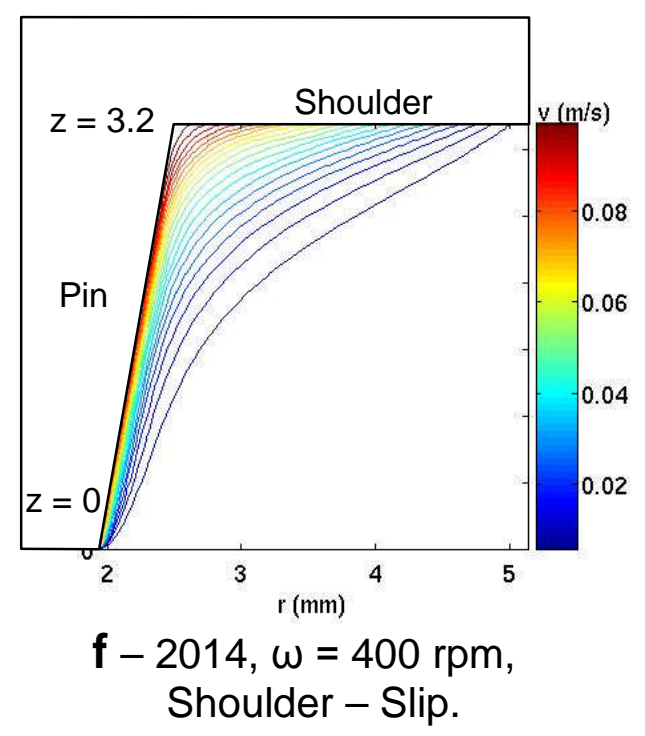

Figure 13 Rotational flow diagrams from the 2 dimensional axisymmetric model. All models use a welding speed of $200 \mathrm{~mm} / \mathrm{min}$. The material, rotation speed and boundary condition under the shoulder are indicated for each of the cases (a-f). 

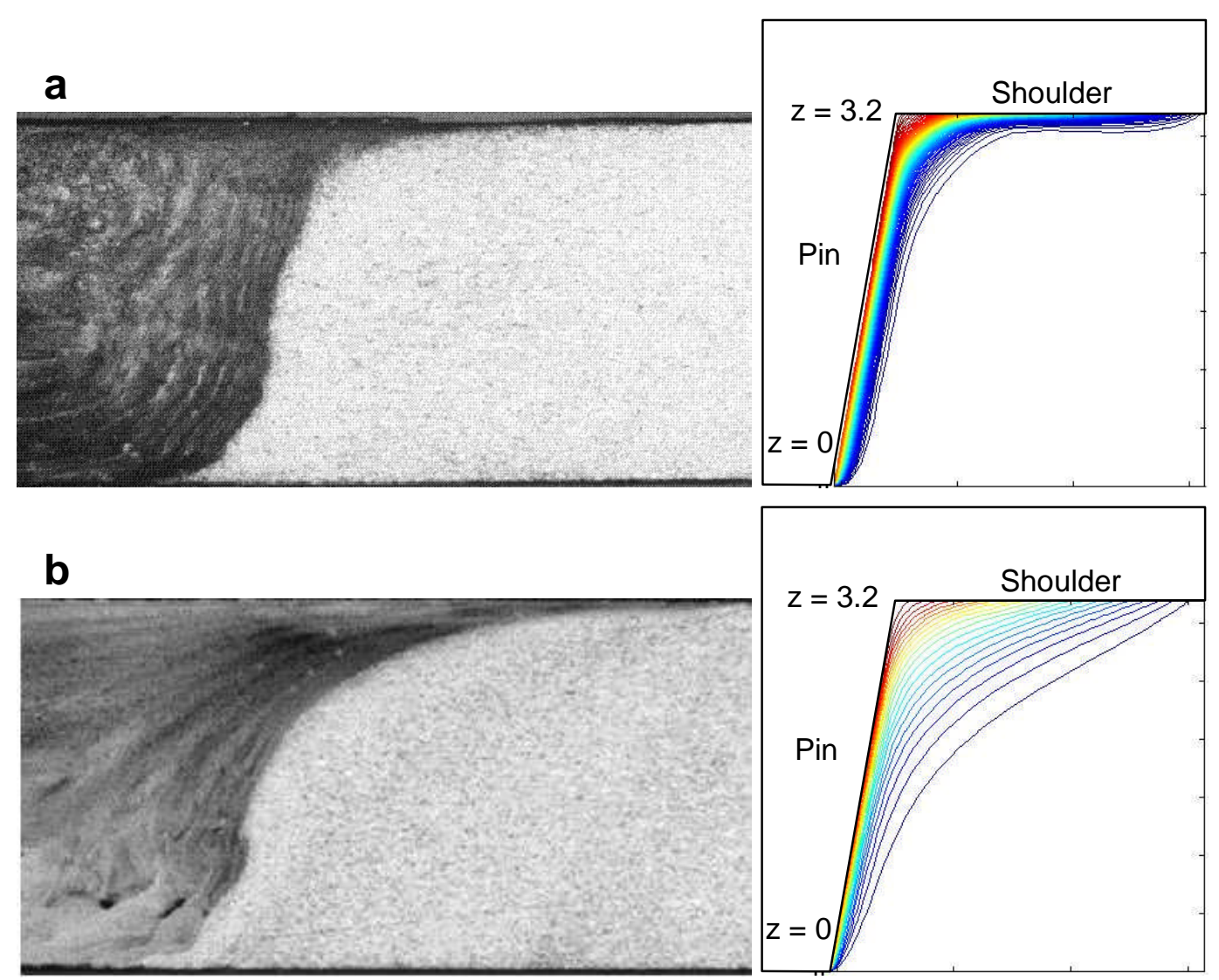

Figure 14 Weld macrosections and corresponding rotational flow diagrams from the welds that used a welding speed of $200 \mathrm{~mm} / \mathrm{min}$ and rotation speeds of (a) $1600 \mathrm{rpm}$ and (b) 400 rpm. The models use the 2014 material properties, and a slip condition at the shoulder. 